OPEN ACCESS

Edited by:

Shanmugasundaram Ganapathy-Kanniappan,

Johns Hopkins School

of Medicine, USA

Reviewed by:

Egidio lorio,

Istituto Superiore di Sanità, Italy

Giorgio Stassi,

University of Palermo, Italy

${ }^{*}$ Correspondence:

Seema Gupta

sgijijagmail.com;

Amrita Roy

dr_amritaroy@yahoo.com;

Bilikere S. Dwarakanath

dwarakanath@sriramachandra.edu.in

tThese authors have contributed equally to this work.

Specialty section: This article was submitted to Cancer Molecular Targets and Therapeutics, a section of the journal Frontiers in Oncology

Received: 17 January 2017 Accepted: 24 March 2017

Published: 12 April 2017

Citation:

Gupta S, Roy A and Dwarakanath BS (2017) Metabolic Cooperation and Competition in the Tumor Microenvironment: Implications for Therapy. Front. Oncol. 7:68. doi: 10.3389/fonc. 2017.00068

\section{Metabolic Cooperation and Competition in the Tumor Microenvironment: Implications for Therapy}

\author{
Seema Gupta ${ }^{1 * t}$, Amrita Roy ${ }^{2 * \dagger}$ and Bilikere S. Dwarakanath ${ }^{3 * \dagger}$ \\ ${ }^{1}$ Georgia Cancer Center, Augusta University, Augusta, GA, USA, ${ }^{2}$ School of Life Sciences, B. S. Abdur Rahman Crescent \\ University, Chennai, India, ${ }^{3}$ Central Research Facility, Sri Ramachandra University, Chennai, India
}

The tumor microenvironment (TME) is an ensemble of non-tumor cells comprising fibroblasts, cells of the immune system, and endothelial cells, besides various soluble secretory factors from all cellular components (including tumor cells). The TME forms a pro-tumorigenic cocoon around the tumor cells where reprogramming of the metabolism occurs in tumor and non-tumor cells that underlies the nature of interactions as well as competitions ensuring steady supply of nutrients and anapleoretic molecules for the tumor cells that fuels its growth even under hypoxic conditions. This metabolic reprogramming also plays a significant role in suppressing the immune attack on the tumor cells and in resistance to therapies. Thus, the metabolic cooperation and competition among the different TME components besides the inherent alterations in the tumor cells arising out of genetic as well as epigenetic changes supports growth, metastasis, and therapeutic resistance. This review focuses on the metabolic remodeling achieved through an active cooperation and competition among the three principal components of the TME-the tumor cells, the T cells, and the cancer-associated fibroblasts while discussing about the current strategies that target metabolism of TME components. Further, we will also consider the probable therapeutic opportunities targeting the various metabolic pathways as well as the signaling molecules/transcription factors regulating them for the development of novel treatment strategies for cancer.

Keywords: tumor microenvironment, metabolic reprogramming, metabolic cooperation, Warburg effect, cancerassociated fibroblasts, immune network, cancer cell metabolism

\section{INTRODUCTION}

One of the important hallmarks of tumor cells is the metabolic reprogramming, where the tumor cells metabolize glucose even in the presence of abundant oxygen (aerobic glycolysis), widely referred to as the Warburg effect (1). This reprogramming is purported to facilitate the survival and growth of transformed cells by enhancing macromolecular synthesis and antioxidant defense, besides the energy production.

Tumor cells in a solid tumor coexist with different types of host cells like the fibroblasts, cells of the immune system like lymphocytes and macrophages, and the endothelial cells constituting the blood vessels besides a host of secreted factors generated by the tumor as well as non-tumor cells. 
Through the paracrine signaling, tumor cells constantly modify the environment that facilitates the survival and growth of the tumor, as well as provides escape from immune surveillance $(2,3)$. The metabolic pattern in a cell is not merely governed by the availability of substrates but is also influenced by the signaling pathways stimulated by the metabolites and the environmental factors (4). The metabolic phenotype of fibroblasts and subsets of lymphocytes within the tumor microenvironment (TME) show a considerable degree of heterogeneity (5), while their stimulation leading to proliferation and functional maturity is invariably preceded by the reprogramming of the metabolism $(6,7)$. It is increasingly becoming clear that the TME consisting of extracellular matrix (ECM), abnormal stroma, and altered vasculature has a strong role in shaping the metabolic phenotype of tumor cells, besides the genetic and epigenetic changes that results in the reprogramming of the cancer cell metabolism $(8,9)$.

Accumulating evidences strongly support the notion that a metabolic dependence exists between the tumor cells and the cells in the stroma, which show temporal and context-dependent variations that provide support to the tumor cells through the shuttling of metabolic intermediates and oxidative stress components leading to signaling changes in the tumor as well as cells in the microenvironment including stromal cells and cells of the immune network $(10,11)$. Current understanding of the metabolic reprogramming in tumors, including the interplay with oncogenic processes and their implications for diagnosis and developing therapeutics has been extensively reviewed and so is the diversity of the metabolic pattern in immune network and their reprogramming following stimulation (12-20). This review focuses on the metabolic reprogramming in the tumor milieu consisting of the tumor cells and cells in the microenvironment for identifying suitable targets for developing newer therapeutic approaches.

\section{COMPONENTS OF TUMOR MICROENVIRONMENT}

In the last two decades with the emerging knowledge on TME, the understanding about the host-tumor interactions within the TME has attained new dimensions. The cellular milieu within a solid tumor consists of a myriad combination of cells, signaling molecules, and ECMs. All these form a heterogeneous medium around the tumor cells known as the tumor stroma or the TME $(21,22)$. The diverse array of cells within the TME originates from the surrounding host tissues and could be either hematopoietic or mesenchymal in origin. The hematopoietic cells in TME are the B cells, T cells, neutrophils, natural killer (NK) cells, and macrophages while the fibroblasts, adipocytes, endothelial cells, and pericytes are the mesenchymal component of TME. Collectively, these cells comprise up to $50 \%$ of the total mass of a solid tumor (23).

The neovasculature that develops within a growing tumor mass is also an integral structural component of the TME and is essential for the development of the pro-tumorigenic atmosphere within the solid tumor. However, the tumor vasculature is larger in size compared to their normal counterparts and hence fails to penetrate deep within the tumor tissue $(24,25)$. Consequently, the TME becomes progressively devoid of oxygen and energy precursors from the periphery toward the core of the solid tumor. The resultant hypoxia and the nutritional stress in turn initiates a complete metabolic remodeling in the neighboring host cells that create the classical pro-tumorigenic TME including lowering of the extracellular $\mathrm{pH}(\mathrm{pHe})$ due to $\mathrm{H}^{+}$and lactate generated by hypoxic cancer cells $(26,27)$. Hypoxia and acidosis are thus the two most important characteristics of TME. In fact, abnormally proliferating tumor cells consume increased oxygen leading to progression of hypoxia that further produces an acidic environment by upregulating glycolysis, which in turn increases proton production and results in proton efflux through several types of acid transporters causing acidosis in the TME [reviewed in Ref. (28)]. Acidosis on the other hand suppresses glycolysis and increases mitochondrial respiration in the cancer cells (28-30). This pro-tumorigenic TME fosters tumor growth and proliferation as well as promotes metastasis, augmenting invasiveness and providing protection against immune/chemotherapeutic assaults.

\section{METABOLISM OF THE COMPONENTS OF TME}

\section{Metabolism of the Cancer Cells}

The proliferation of cancer cells requires a continuous and higher rate of supply of energy as well as precursors for macromolecular synthesis. This requirement, following the malignant transformation is ensured by the reprogramming of the metabolism involving enhanced glycolysis, glutaminolysis, and de novo lipid biosynthesis (Figure 1) in preparation for mitosis, which also supports the maintenance of redox balance and evasion of death by apoptotic pathways $(31,32)$. The enhanced glycolysis, despite availability of adequate oxygen supply, metabolizing glucose to lactate was unraveled by Otto Warburg, who referred to this as "aerobic glycolysis" $(1,33)$ and is widely known as the "Warburg phenotype". Metabolic reprogramming of cancer cells is a complex interplay of various signaling pathways [like phosphoinositide-3-kinase (PI3K), mammalian target of rapamycin (mTOR), Akt, PTEN, AMP-activated protein kinase (AMPK), and Notch] regulated by a plethora of transcription factors including hypoxia-inducible factor (HIF) $1 \alpha, \mathrm{c}-\mathrm{Myc}$, and p53 $(12,34,35)$. Mutation of c-Myc has also been observed in cancer cells that increases the transcriptional activities of enzymes involved in glycolysis and glutaminolysis $(36,37)$. Various microRNAs involved in the process of metabolic reprogramming linked to several oncogenic signaling pathways have been recently reviewed in Ref. (12).

Underlying factors that contribute to the Warburg phenotype or aerobic glycolysis include alterations in the mitochondrial functional status, upregulation of rate-limiting enzymes of glycolysis and intracellular $\mathrm{pH}$ regulation, loss of $\mathrm{p} 53$ function, and the presence of hypoxia in solid tumors (38). Hypoxia-induced HIF1 activates the transcription of several genes including the genes responsible for upregulating glycolysis such as glucose transporters (Glut), Glut-1 and 3; glycolytic enzymes, hexokinase 1/2 (HK I/II) and pyruvate kinase M2 (PKM2), and genes involved in the inhibition of oxidative phosphorylation, pyruvate dehydrogenase kinase 1 (PDK1), and lactate dehydrogenase-A 


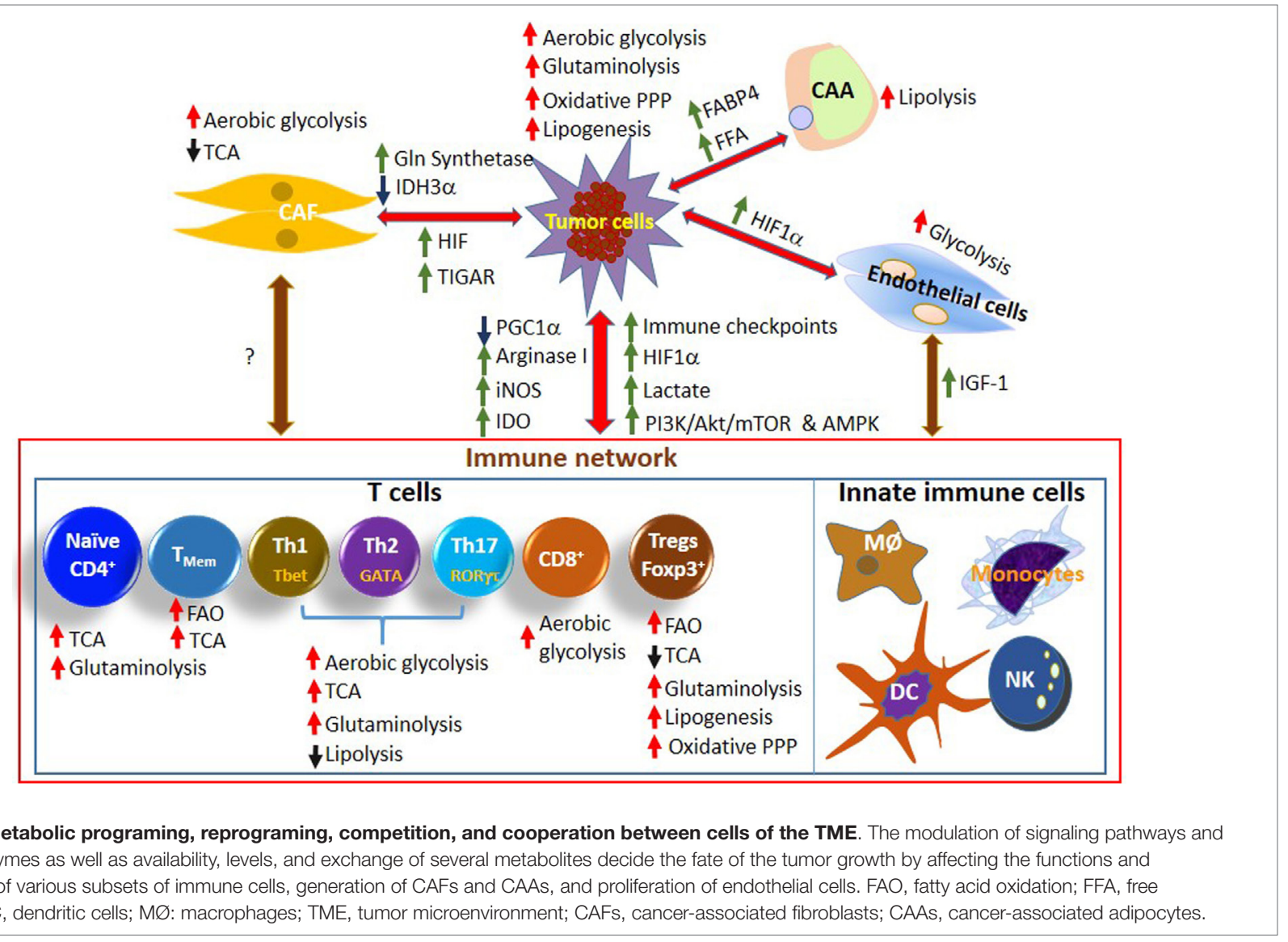

(LDH-A) (39-41). High expression of HIF1 $\alpha$ and Glut-1 are associated with poor prognosis in cancer patients (11). Furthermore, HIF $1 \alpha$ supports energy supply to hypoxic tumor cells driving an anaerobic glycolysis by upregulating monocarboxylate transporter 4 (MCT4) that exports the lactate out of the cells (42) and influencing carbonic anhydrase IX (CAIX) to prevent the intracellular acidification (43). HIF1 also helps in reducing mitochondrial activity and reactive oxygen species (ROS) generation from oxidative phosphorylation by regulating the expression of BCL2/adenovirus E1B $19 \mathrm{kd}$-interacting protein 3 (BNIP3) and cytochrome oxidase COX-4 subunit composition $(44,45)$. In addition to HIF1-mediated effects, several HIF-independent pathways (such as mTOR) regulate the cancer cell metabolism (28). Under nutrient stress conditions in the TME, mTOR modulates several energy requiring processes such as mRNA translation, metabolism, and autophagy $(46,47)$. The upregulated glycolysis of the cancer cells and blood perfusion also influence the intracellular and pHe in the TME $(48,49)$. Reduced blood perfusion and preference for use of glycolysis by the cancer cells for their energy needs result in increased lactic acid production. Generation of protons during hydrolysis of ATP as well as hydration of carbon dioxide $\left(\mathrm{CO}_{2}\right)$ by carbonic anhydrases (CA) also contributes to acidosis of the TME as both lactic acid and protons are exported out of the cancer cells over time $(43,50)$. Several MCTs, vacuolar type $\mathrm{H}^{+}$-ATPases, $\mathrm{Na}^{+} / \mathrm{H}^{+}$exchangers, and other acid-base transporters are involved in the export of lactic acid and protons and their inefficient removal from the tumor interstitial space causes the acidification of the extracellular TME $(28,48)$. While acute acidosis decreases cancer cell proliferation and increases apoptosis $(51,52)$, chronic acidosis acts as a selective pressure leading to acquisition of multiple genomic mutations beneficial for cancer cell growth and adaptation $(53,54)$. Treatment of prostate cancer cells with acidosis is shown to reduce Akt activity (29). Therefore, reduced Akt activity may enhance the activity of $\mathrm{Na}^{+} / \mathrm{H}^{+}$transporter $\mathrm{NHE}-1$ causing increased proton export and cell proliferation $(55,56)$. Although hypoxia and acidosis in the TME are shown to induce distinct biological effects, several reports have shown both synergistic as well as antagonistic effects on tumor cell response when treated simultaneously with these stimuli [reviewed in Ref. (28)]. In cases of oral squamous cell carcinoma, proteins associated with glucose and lactate metabolism are often found to be co-localized in the hypoxic areas $(57,58)$ and therefore an analysis of their combined expression can be used for early diagnosis and prognosis (59).

Although regulators of various signaling pathways contributing to the Warburg phenotype would naturally be pertinent targets for designing anticancer therapeutics and adjuvant, development of effective therapies targeting this phenotype has remained a challenge till date (60). However, the enhanced glucose uptake of tumors has been widely exploited for the non-invasive detection and grading of tumors by positron emission tomography using the F-18-labeled glucose analog 2-deoxy-D-glucose (FDG) (61). 
It is increasingly believed that a better understanding of the mechanisms underlying Warburg effects will facilitate the design of effective therapies targeting the reprogramming of metabolism (14). Renewed interest in unraveling the mechanisms underlying the development of Warburg phenotype and its relationship with therapeutic resistance of tumors $(12,62-65)$ holds great promise in the future for developing novel therapeutic strategies targeting metabolic reprogramming of tumors (60).

In a rapidly proliferating tumor cell, alternative pathways of glucose metabolism, like the pentose phosphate pathway (PPP), are essential for generating important biomolecules like NADPH and ribose sugars (Figure 1). For the tumor cells, the NADPH is essential to fulfill various metabolic requirements like ATP production, lipogenesis as well as for eliminating the oxidative stress. Similarly, the ribose sugar as an integral part of the nucleotides is essential for rapidly dividing cells. In fact, a high ratio between the oxidative and non-oxidative branches of PPP is known to promote the proliferation of several types of cancer cells $(66,67)$. In HCT116 colon adenocarcinoma cells, regulators of cell cycle progression like CDK4 and 6 have also been found to be involved in maintaining the crucial balance between the two branches of PPP (68).

To support the overall growth, cancer cells need adequate amount of macromolecules like nucleic acids, lipids, and proteins. Highly proliferative cancer cells are associated with a strong dependency on lipid and cholesterol, which are satisfied by either enhanced uptake of exogenous (or dietary) lipids and lipoproteins or by increasing the activation of endogenous synthesis (69). Indeed, the lipid droplets consisting of cholesterol and other lipids found in some of the tumor cells are now considered as hallmarks of the degree of aggressiveness of the cancer (69). Specific lipids are now known to mediate intracellular oncogenic signaling, defense against endoplasmic reticulum stress, and interactions with cells of the TME (69). Since HIF1 inhibits mitochondrial oxidative phosphorylation, it also inhibits the fatty acid synthesis from glucose-sourced carbon as pyruvate is not utilized in the mitochondria $(28,70)$. Therefore, to meet the increasing demands of ATP and the lipids, growing tumor cells increase the uptake and synthesis of glutamate as an alternative carbon source. Tumor cells utilize glutamine as a nitrogen donor for essential amino acid and nucleotide biosynthesis as well as to generate $\alpha$-ketoglutarate which can be channelized toward tricarboxylic acid (TCA) cycle for energy production $(71,72)$. Glutamine can enter the cell through glutamine transporters like SLC1A5 (ASCT2) and SLC38A5. The levels of these receptors especially that of SLC1A5 are found to be overexpressed in breast and prostate cancer cell lines and pharmacological inhibitors such as benzylserine (BenSer) and L- $\gamma$-glutamyl- $p$-nitroanilide (GPNA) or shRNA-mediated inactivation/suppression of the glutamine transporter has been found to stall the proliferation of tumor cells $(73,74)$ (Table 1). The uptake of glutamine in tumor cells is in turn governed by its lactate uptake as acidic TME supports activation of p53 and increases glucose 6-phosphate dehydrogenase (G6PD) and glutaminase 2 (GLS2) (75). Within the tumor cells, lactate obtained from the neighboring tumor stroma stabilizes the HIF $2 \alpha$ which in turn activates the oncogene c-Myc and upregulates the expression of both glutamine transporter
ASCT2 and glutaminase 1 (GLS1) - thus ensuring a steady flux of glutamine in the cells (76) (Figure 2). Further, in addition to the glutamine, metabolism of other amino acids such as arginine, tryptophan, glycine, serine, and branched chain amino acids (BCAAs, leucine, isoleucine, and valine) play an important role in tumorigenesis and TME (77).

\section{Metabolism of the Immune Cells Cells of the Immune Network}

Solid TME is infiltrated by various heterogeneous immune cell types that work in a coordinated fashion against the tumor antigens (Figure 1). Their proliferation, effector function, and differentiation are regulated by several signals that are influenced by the metabolic activity. Although several types of innate immune cells such as NK cells, macrophages, and dendritic cells (DCs) play an important role in mediating the antitumor effects (Figure 1), here we are focusing more on immune functions mediated by $\mathrm{T}$ cells.

Transition of $\mathrm{T}$ cells from naïve to effector and to memory phenotype requires specific metabolic programing and reprograming to match their proliferation status and function (78). The naive and memory $\mathrm{T}$ cells utilize oxidative phosphorylation to derive ATP for their needs. However, proliferating lymphocytes reprogram their metabolism and switch to glycolysis for fulfilling the energetically demanding processes of cell division and effector functions. Presence of glucose and amino acids such as glutamine is essential to support the changing demands of proliferation and biosynthesis utilizing distinct metabolic pathways $(79,80)$. Further, different $\mathrm{T}$ cell subtypes depend on different metabolic pathways for their energy needs and thus metabolism plays a key role in determining the T cell fate, differentiation, and function (Figure 1). In addition to the metabolic cooperation between different cell types, other factors such as oxygen pressure and presence/availability/levels of different metabolites affect the proper functioning of immune cells. Therefore, TME plays an important role in determining the $\mathrm{T}$ cell-mediated immune response as activated $\mathrm{T}$ cells go from an oxygen and nutrient-rich environment in the periphery to the hypoxic and nutrient-poor environment of solid tumors (13).

\section{T Cell Metabolism}

There are several reasons that lead to progression of cancers. Cancers that have weakly immunogenic antigens can evade killing (81). Cancers can also evade killing due to T cell dysfunction, anergy, exhaustion, senescence, or hypo-responsiveness $(82,83)$. Although several factors may affect the function of $\mathrm{T}$ cells, metabolic competition between tumor cells and $T$ cells is now emerging as one of the major contributors for tumor escape. Like the other normal cells in the body, $\mathrm{T}$ cells have specific energy requirements according to their function and activation status (Figure 1). Both $\mathrm{CD}^{+}$and $\mathrm{CD} 8^{+} \mathrm{T}$ cells in resting state generate most of their energy using TCA cycle as they have low metabolic requirements (84). They need limited biosynthesis and oxidize pyruvate and lipids as well as amino acids for energy production. However, when the $\mathrm{T}$ cells are activated, they shift to glycolysis and other anabolic pathways and use the metabolic intermediates of TCA cycle to synthesize proteins, lipids, and nucleic acids (13, 
TABLE 1 | Therapeutic agents (small molecules) targeting different cells of the TME and their associated metabolism.

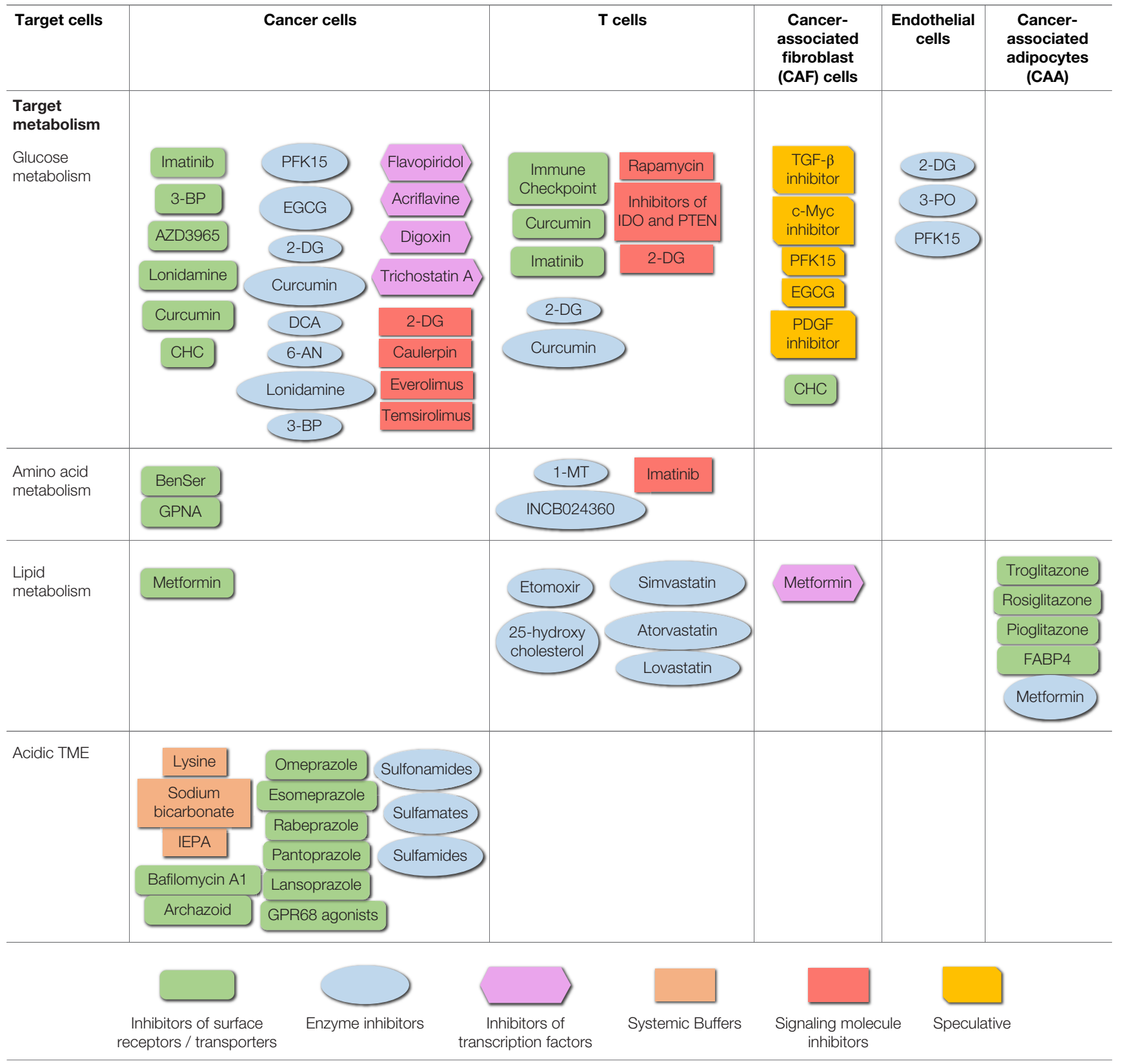

85). This switching provides several advantages as it leads to rapid turnover of ATP (although aerobic glycolysis is less efficient as number of ATP molecules generated is much less than oxidative phosphorylation); decreased production of ROS; generation of metabolic intermediates needed for growth and proliferation; and accommodation of $\mathrm{T}$ cell survival in hypoxic environment generally present in the solid tumors [reviewed in Ref. (20)]. $\mathrm{CD}^{+} \mathrm{T}$ cells show enhancement in both glycolysis and oxidative phosphorylation upon activation, while $\mathrm{CD}^{+} \mathrm{T}$ cells may increase only glycolysis making them more sensitive to availability of glucose $(5,13)$. Activated $\mathrm{T}$ cells show increased expression of Glut-1 on their surfaces for facilitating enhanced uptake of glucose (86). Extracellular signals mediated by growth factors play a significant role in increased expression and membrane localization of the transporters. The expression of growth factors and their receptors change with the activation status of the T cells (87). For example, IL7 receptor expression increases in naïve cells, decreases in activated cells with increased dependence on IL2 and then again increases during differentiation of T cells to memory T cells (88). The change in the levels of the growth factors is reflected in change in the cellular metabolism and their withdrawal results in removal of nutrient transporters from the cell surface and decreased glycolysis among other metabolic changes $(89,90)$. Increase in glycolysis is generally also accompanied with increase in glutamine oxidation and decrease in lipid oxidation $(13,80)$ (Figure 1). Glutamine metabolism may also regulate the 


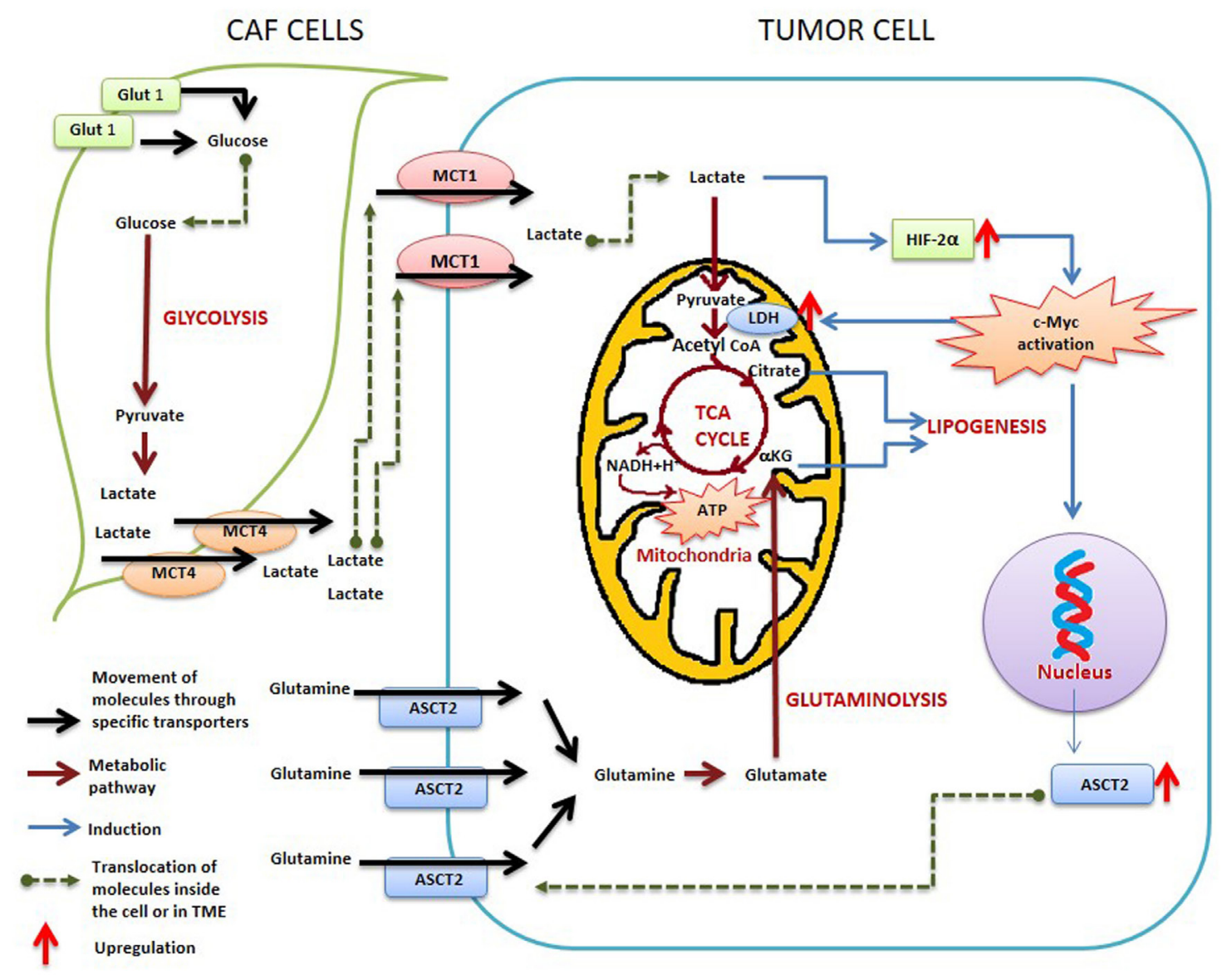

FIGURE 2 | Metabolic reprogramming between cancer-associated fibroblasts (CAFs) and tumor cells within tumor microenvironment.

balance of effector and regulatory T cells (Tregs). Loss of the neutral amino acid transporter protein, ASCT2 in T cells resulted in impaired generation and function of Th1 and Th17 cells without altering Tregs generation (91). Similarly, arginine regulates the expression of components of T cell receptor (TCR) (92) and cell cycle progression in T cells (93).

The induction of aerobic glycolysis during $\mathrm{T}$ cell activation is dependent on the PI3K pathway (94). Downstream of PI3K pathway, Akt has been shown to affect the expression of Glut-1 and its translocation to the cell membrane $(86,95)$. Akt is known to control the activation status of MTOR that controls protein synthesis, mitochondrial activity, and proliferation $(96,97)$. Therefore, in addition to the extracellular signals mediated by several growth factors, PI3K/Akt/mTOR signaling triggered by TCR and co-stimulatory signal through CD28 play major roles in metabolic reprograming of $\mathrm{T}$ cells during their activation (94). mTOR upregulates c-Myc and HIF1 $\alpha$ although only c-Myc is required for the glycolytic switch as its early upregulation is crucial in the activation process of $\mathrm{T}$ cells (98).

Following activation and division, $\mathrm{T}$ cells differentiate into different subsets that switch on distinct metabolic pathways appropriate for their function. mTOR and other signaling pathways such as Myc and HIF $1 \alpha$ play significant roles in determining these phenotypes in effector T cells $(99,100)$. T helper (Th) cells; Th1, Th2, and Th17 rely more on aerobic glycolysis where mTORC1 and 2 help in deciding the metabolic phenotype while Tregs and memory $\mathrm{T}$ cells achieve their metabolic needs principally through fatty acid oxidation (FAO) that is controlled by AMPK (101). The decrease in dependence on glycolysis and utilization of lipid metabolism may play a role in survival advantage of Tregs and memory T cells $(102,103)$ (Figure 1).

\section{Metabolism of the Mesenchymal Cells CAF Metabolism}

Cancer-associated fibroblast or CAF are a group of specialized fibroblasts that is considered to be the principal non-cancerous cell type within the TME. In normal tissues, the fibroblasts remain embedded in a comparatively dormant state in the ECM. They synthesize and secrete collagen, fibrous proteins like reticulin and elastin, proteoglycans, glycoproteins, and various other components of the ECM that act as a cementing material among the cells and helps in maintaining a cohesive organ structure (104).

Within the TME, the normal fibroblasts transform into a highly synthetic, metabolically active, contractile form that resembles the "activated myofibroblasts" (105) observed in the wound site during tissue damage and repairing process. The 
tumor cells require the presence of such activated fibroblast or CAF in their vicinity to generate a favorable atmosphere for them. The CAFs are known to actively promote proliferation and differentiation of tumor cells as well as support angiogenesis and metastasis by promoting matrix remodeling and epithelial to mesenchymal transition (EMT) (106-108). Even the enrichment of stroma/CAFs within the tumor tissue has a direct correlation with the tumor size and a negative impact on the clinical prognosis (109) - as observed in cases of gastric signet ring cell carcinoma-indicating the profound impact of CAFs on overall tumor biology.

In recent years, growing knowledge about TME and the metabolic crosstalk between the cancer cells and the associated CAF cells have generated tremendous interest regarding the bioenergetics of the various cellular compartments of the TME. The metabolic hallmark of the CAF is their high glycolysis (Figures 1 and 2). Several studies have indicated the presence of an increased expression of MCT4 in CAF-mediating lactate efflux from them $(110,111)$ (Figure 2). On the other hand, in the osteosarcoma cells, an increased expression of MCT1 mediating lactate influx has been observed (112). Similarly, increased production of lactate associated with upregulation of MCT1 and 4 has been observed in CAFs associated with breast (113) and bladder (114) cancer cells. Such observations clearly indicate the dependence of the cancer cells on metabolites provided by the CAF cells.

The lactic acid present in the TME along with the hypoxic environment is also known to mediate the transformation of the macrophages from M1 to a pro-tumorigenic M2 phenotype through a HIF $1 \alpha$-mediated pathway $(115,116)$ by directly inducing M2-like gene expression (augmented expression of VEGF, Arg1, PKM2, etc.) in tumor-associated macrophages (TAMs) $(116,117)$. Recent studies have also suggested that the excess lactic acid produced by the heightened glycolysis observed in $\mathrm{CAF}$ - is one of the chief regulators that orchestrates the metabolic transformation of the different cells that reside within the TME (118) (Figure 2).

\section{Endothelial Cell Metabolism}

Like the cancer cells and CAFs, endothelial cells also rely on glycolysis to sustain themselves in the hypoxic TME (Figure 1). To support the cancer cells, endothelial cells also need to maintain a high degree of proliferation. The hypoxic environment of TME along with pro-angiogenic signals such as VEGF lead to the upregulation of glycolytic enzymes like glyceraldehydes3 -phosphate dehydrogenase $(\mathrm{GAPDH})$ and glycolytic regulators like phosphofructokinase (PFK)-2/fructose-2,6-bisphosphatase 3 (PFKFB3) and Glut-1 thereby promoting glycolytic mode of metabolism [reviewed in Ref. (119)].

\section{Metabolism of Adipocytes}

Adipocytes are one of the important components of TME (120). In the normal tissue, adipocytes uptake the fatty acids, activate them, and transfer the resulting CoA derivatives to glycerol forming triacylglycerols (121). However, adipose cells need glucose for the synthesis of triacylglycerol. Most of the fatty acids formed on hydrolysis are reesterified if glycerol 3-phosphate is abundant, while they are released into the plasma if glycerol 3-phosphate is scarce because of a paucity of glucose. Thus, the glucose level inside adipose cells is a major factor in determining whether fatty acids are released into the blood (121).

\section{METABOLIC COOPERATION AND COMPETITION IN THE TME}

Tumor microenvironment is very complex and heterogeneous where various types of cells including cancer, immune, endothelial, fibroblasts, etc. reside and interact with each other in a unique environment (122). Tumor cells are highly metabolic and other cells surrounding the tumor either compete with the cancer cells causing metabolic antagonism or support them by forming a metabolic symbiosis (15). A competition between cells of the TME occurs as demands for resources in the microenvironment are high. Tumors reprogram their metabolism in such a way that either directly supports tumor proliferation or shapes the microenvironment favoring tumor cell survival (15). For example, tumors cells are known to express and release several cytokines, lactate, and indoleamine 2,3-dioxygenase (IDO) that help in inhibiting the proliferation and function of $\mathrm{T}$ cells. Further, increase in HIF signaling and activation of oncogenes in the cancer cells improve their metabolic fitness resulting in deprivation of vital metabolites such as glucose and glutamine for stromal cells (15). This competition between the different cells in the TME promotes immune suppression due to the exhaustion of immune cells $(82,123)$. In turn, antitumor immune cells such as effector T cells and cytotoxic T lymphocytes (CTLs) reprogram their metabolism to robust aerobic glycolysis and glutaminolysis leading to metabolic antagonism with the tumor cells while the pro-tumoral immune suppressive cells such as Tregs, myeloidderived suppressor cells (MDSCs), and M2 TAMs utilize the products generated from tumor metabolism forming a metabolic cooperation within the TME (15).

Studies in the last two decades have established CAF as one of the dominant factors that govern the proliferation of tumor cells and progression of tumor growth. CAFs appear to exert an influence on proliferation through paracrine signaling. The conditioned media from the cultures of CAFs of oral carcinoma has been found to augment the proliferation of tongue cancer cells suggesting the presence of a paracrine machinery involved in the process (124). Further, CAFs isolated from prostate carcinoma has been shown to augment the rate of proliferation of even normal prostate epithelia cells $(125,126)$ thus emphasizing the growth promoting influence of the CAFs. Similarly, in the TME, adipocytes present in the vicinity of the tumor undergo several functional changes to become cancer-associated adipocytes (CAA) and support growth of the tumor (120).

\section{Metabolic Reprograming of T Cells in the TME}

Several studies have suggested that $\mathrm{T}$ cells become anergic or exhausted in the established tumors leading to their dysfunction and immune escape of tumors. Hypoxia and availability of various metabolites and nutrients are the two most important properties of the TME driving the metabolic reprograming in these cells. 


\section{Effect of Hypoxia on T Cell Metabolism}

As the metabolic pattern and functionality of the immune cells are dependent on the cytosomatic cues and the partial oxygen tension of the surrounding medium, the immune cells suffer a vast transformation as they travel deeper into the hypoxic interior of the solid tumor. Hypoxia is one of the most important cues in the TME that modulates the metabolism of cancer as well as all cell types of innate and adaptive immune system thereby potentiating tumor progression. Presence of hypoxic regions in solid tumors enhances the pro-tumorigenic immune suppressive environment. HIF family of transcription factors plays a central role in the cellular responses of both tumor and stromal cells. Both oxygen-dependent and oxygen-independent regulation of HIF1 $\alpha$ has been reported in these cells (127).

Under hypoxic conditions, HIF1 $\alpha$ gets activated and regulates the expression of several enzymes involved in glycolysis such as LDH and PDK1 (128) and glycolysis-related genes, GLUT-1 and PFKFB3 (129). This results in increased glycolysis and decreased oxidative phosphorylation and oxygen consumption (130). Increased lactic acid production by tumor cells under hypoxic conditions inhibits the proliferation and functions of $\mathrm{T}$ cells of the adaptive immune system (Figure 1). Controversial role of HIF signaling has been reported in determining the differentiation of $\mathrm{CD}^{+}$naïve T cells into either Th17 or Treg cells with some reports suggesting induction and others inhibition of these cell types (131-133). HIF1 $\alpha$ has been reported to target Foxp3 for proteasomal degradation and therefore inhibits Treg differentiation and shifts the balance toward Th17 (131). Dang et al. also showed that HIF $1 \alpha$ shifts Th2 to Th17 differentiation by direct upregulation of IL17 gene and increased transcription of RAR-related orpha receptor $\gamma(\mathrm{ROR} \gamma \mathrm{t})$ (132). However, Th17 induction is shown to be accompanied with enhanced glycolysis mediated by mTOR/ HIF $1 \alpha$ signaling as upregulation of HIF $1 \alpha$ results in increased expression of Glut- 1 and therefore glycolysis in Th17 cells (134) unlike Tregs that depend on FAO for their metabolic needs. Therefore, more studies are needed to understand the role of hypoxia/HIF-mediated signaling/glycolysis in different subsets of $\mathrm{T}$ cell metabolism, differentiation, and function.

In addition to $\mathrm{T}$ cells, hypoxia has also been shown to either subvert the antitumorigenic functions toward pro-tumorigenic functions or enhance the immune suppressive functions of the cells of the innate immune system; TAMs, and tumor-associated neutrophils (TANs) (127). Hypoxic environment in the tumors promotes the polarization of TAMs toward pro-tumorigenic M2 phenotype either directly by inducing M2-like gene expression (augmented expression of VEGF, Arg1, PKM2, etc.) in TAMs (135) or due to hypoxic metabolism by tumor cells (elevated lactate levels) in HIF1 $\alpha$-dependent manner (116). In addition to this metabolic symbiosis between tumor cells and macrophages affecting the immune response, tumor hypoxia-mediated recruitment of endothelial cells results in interaction of these cells with M2 macrophages as they also play significant role in angiogenesis $(127,136)$ (Figure 1). More recently, hypoxic TAMs have been shown to upregulate the expression of REDD1, a negative regulator of mTOR hindering glycolysis and angiogenic response revealing a functional link between TAM metabolism and tumor angiogenesis (137). Cross-talk between these cells thus influences the availability of oxygen, cellular metabolism, as well as the antitumor immune response (127).

The transformation of the macrophages from M1 to M2 phenotype can be considered as the cornerstone of the metabolic immune-compromised milieu of the TME. The M1 and M2 macrophages not only differ in their immunological functions but vary greatly in their metabolic dependence as well. The M1 macrophages, providing protection against bacterial infection, depends principally on glycolysis for ATP generation but the M2 macrophages, populating the sites of healing wounds, utilize the FAO and oxidative phosphorylation for their sustenance (138) and does not compete with the tumor cells for resources in a nutritionally challenged TME. It is tempting to speculate that this scarcity of resources within the TME could also act as competitive inhibitor that quickly eliminates the glycolysis dependent, antitumorigenic M1 macrophages from the TME. The M2 type macrophages, but not the M1 type, also secrete insulin-like growth factor-1 (IGF-1), which promotes tissue regeneration (139) and angiogenesis $(139,140)$ hence might be involved in replenishing the TME (Figure 1).

The different types of $\mathrm{T}$ cells that are known to infiltrate the TME include the memory T cells, Th 1, Th2, and the Th 17 cells. The memory $T$ cells are cytotoxic and are supported by the Th 1 cells and their abundance is related with positive clinical outcome whereas the higher titer of $\mathrm{Th} 2$ and $\mathrm{Th} 17$ leads to poor clinical prognosis (141). Within the solid tumor, the M2 macrophages create a protumorigenic atmosphere by strongly promoting the generation of the Th2 cells while actively suppressing the proliferation of antitumorigenic $\mathrm{T}$ cells. In fact the M2 bias along with ligands like galectin-9-secreted by the tumor cells (142) - is known to stem the proliferation of peripheral monocytes as well as induce Th1 cell apoptosis (143). Th2 along with HIF1 $\alpha$ is also known to promote the differentiation of the Th17 subset of T cells. Th17 and its associated interleukins like IL17, IL23, IL25, etc. are reportedly involved in carcinogenesis [induce colon tumorigenesis through a STAT3-mediated pathway (144)], tumor progression (145), and subsequent negative clinical outcome (146). Similarly, it has been demonstrated that HIF1 $\alpha$ is essential for regulation of metabolic activity in neutrophils and the absence of HIF $1 \alpha$ resulted in drastic reduction in ATP and the killing function of neutrophils (147). Hypoxia also enhances the suppressive function of MDSCs thereby suppressing antitumor immunity. Furthermore, hypoxia is known to increase HIF signaling and upregulate HIF targets and increase the expression of arginase I causing increase in MDSC suppressor function (148).

Thus, through ECM remodeling, growth factor signaling, and evasion of immune response recruited stromal cells enhance tumorigenesis. Further, hypoxic TME results in metabolic symbiosis between hypoxic and normoxic compartments of the tumor. The products of highly glycolytic hypoxic cells such as lactate are used by normoxic cells to produce ATP through oxidative phosphorylation leading to sustained metabolic fitness of the tumor (18).

\section{Metabolites and Nutrients Availability}

Both cancer and activated immune cells depend on aerobic glycolysis for their energy needs as both are highly proliferating. This results in a competition for available nutrients to meet their energy 
and biosynthetic requirements influencing the $\mathrm{T}$ cell metabolism affecting their function, proliferation, as well as differentiation. Tumor cells by utilizing more glucose and glutamine create a state of nutrient deprivation for the $\mathrm{T}$ cells (16). This nutrient deprivation may result in T cells anergy, exhaustion, and death thereby compromising their effector functions (16). A decrease in the glucose concentration due to increased consumption by tumor cells has been shown to metabolically restrict T cells (16, 149). This leads to decreased mTOR activity, glycolytic capacity, interferon- $\gamma(\mathrm{IFN}-\gamma)$ production, and cytolytic activity via production of granzyme and perforin in T cells resulting in tumor progression (150-152). Similarly, depletion of glutamine, which is required for replacing the metabolites removed from TCA cycle for biosynthesis, has been shown to impair the function of T cells (153). Tumor cells also change themselves, for example, by oncogenic mutations resulting in continuous activation of growth and division (154). Furthermore, there may be an increase in the immunosuppressive factors produced either by cancer or other cells in the TME. Growth factor withdrawal also affects the general metabolism (87) because it results in removal of nutrient transporters from the cell surface and decreased glycolysis $(89,90,155)$. Further, deprivation of growth factors leads to a decrease in availability of mitochondrial substrates for oxidative phosphorylation, changes in the mitochondrial morphology, and depolarization of the mitochondrial membrane $(89,90,155)$. These metabolic changes are followed by release of pro-apoptotic factors and commitment to cell death by apoptosis (156). Recently, it has been demonstrated that tumor-infiltrating $\mathrm{T}$ cells have persistent loss of mitochondrial function and mass in a TME-specific effect as signals in TME can repress T cell oxidative metabolism resulting in effector $\mathrm{T}$ cells with modified metabolic needs that cannot be met (157). For example, tumor-infiltrating $\mathrm{T}$ cells showed a loss of peroxisome proliferation-activated receptor (PPAR)-gamma coactivator $1 \alpha(\mathrm{PGC} 1 \alpha)$ that programs mitochondrial biogenesis (157) (Figure 1). Reprogramming of the metabolism through enforced expression of PGC1 $\alpha$ reinvigorated the function of tumor-specific effector $\mathrm{T}$ cells resulting in improved intra-tumoral metabolic and effector functions (157).

More recently, it has been recognized that in addition to $\mathrm{T}$ cell exhaustion, availability of certain metabolites such as lactate, tryptophan and arginine-related metabolites, and phosphoenolpyruvate (PEP) can modulate the activity of tumorinfiltrating lymphocytes (TILs) (158). Ho et al. discovered a new role for the glycolytic intermediate PEP in controlling the activity of effector $\mathrm{T}$ cells (123). They found that PEP regulates the amplitude of TCR-mediated $\mathrm{Ca}^{2+}$ flux and nuclear factor of activated $\mathrm{T}$ cells (NFAT) activation by repressing activity of sarco/ER $\mathrm{Ca}^{2+}$-ATPase (SERCA) in intra-tumoral $\mathrm{CD}^{+} \mathrm{T}$ cells. By overexpressing PEP carboxykinase 1 (PCK1) in $\mathrm{T}$ cells that leads to increased production of PEP, stronger antitumor responses were observed. Similarly, a secondary role has been discovered for glycolytic enzyme, GAPDH in regulating the effector functions of T cells (153). GAPDH inhibits IFN- $\gamma$ mRNA translation when glycolytic rates are low (153). Further, lactic acid production and consequent acidification in the TME are shown to inhibit proliferation and cytokine production in CTLs $(159,160)$. Buffering of lactic acid in vitro $(159,161)$ or in vivo using proton pump inhibitor, Esomeprazole (161) resulted in complete reversal of suppressive effects of lactic acid in CTLs. By suppressing PI3K/Akt/mTOR pathway, lactate can also inhibit glycolysis (29). Lactate-mediated acidification and low $\mathrm{pH}$ in the TME can regulate macrophage polarization and induce arginase I leading to arginine depletion and inhibition of $\mathrm{T}$ cell proliferation and activation $(116,162)$ (Figure 1). Since Tregs prefer oxidative metabolism, it is anticipated that excess lactate can be utilized by Tregs preferentially compared to effector T cells (16). Increased lactic acid also inhibits monocyte-derived DC differentiation and activation (163) although it does not affect Tregs (101). Acidosis in the TME is also shown to stimulate activity of neutrophils (164) while repressing the functions of NK cells $(165,166)$. Succinate and succinate receptor, G protein-coupled receptor 91 (GPR91) have been shown to sense immunological danger $(167,168)$ inducing inflammation, which may be of consequence as succinate levels may drop due to decreased flux through the TCA cycle in the mitochondria.

In addition to glycolysis, amino acid metabolism particularly $\mathrm{L}$-arginine and tryptophan catabolism is also dysregulated in cancers $(71,169)$. Activity of two important enzymes in arginine metabolism, induced nitric oxide synthase (iNOS) and arginase (ARG), is upregulated in several cancers $(170,171)$ (Figure 1). These enzymes create toxic reactive nitrogen species (RNS) such as peroxynitrite that is shown to induce apoptosis in lymphocytes and negatively affect $\mathrm{T}$ cell-mediated immunity in the tumors (172-174). Increased RNS can modulate tyrosine phosphorylation of several proteins leading to downregulation of membrane receptors such as $\mathrm{CD} 4, \mathrm{CD} 8$, and chemokine receptors in T cells (175). Further, enhanced L-arginine metabolism could also be responsible for anergic state of lymphocytes in the TME as addition of inhibitors of ARG and iNOS results in activation of CTLs (176). Altered L-arginine metabolism in the tumor could also lead to local arginine deficiency affecting protein synthesis in T cells $(177,178)$ and therefore impairing the cytokine production and effector function (179). Many tumors are known to lack an enzyme argininosuccinate synthetase 1 and therefore depend on exogenous arginine for growth (180). Tumor-associated myeloid cells (TAMCs) such as MDSCs, macrophages, monocytes, and neutrophils provide arginine to the tumor cells (181). Further, MDSCs in the TME express high levels of arginase-1 and lower arginine levels lead to inhibition of antigen-specific T cell responses due to TCR expression inhibition (178). MDSCs also sequester cysteine resulting in amino acid deprivation and inhibition of T cell activation (182).

Similar to L-arginine, local depletion of tryptophan results in T cell apoptosis and anergy (183). Increased IDO enzyme activity in the tumor cells results in accumulation of kynurenine and its derivatives and tryptophan depletion that inhibit proliferation and activation of immune cells (184) and is associated with extensive disease and immune suppression (183, 185-187). IDO enzymes are intracellular and are not secreted; however, the metabolic effects of these enzymes are not restricted to the expressing cells (183). The neighboring cells present in the TME respond to the depleted levels of tryptophan and also the secreted kynurenine thereby efficiently inhibiting the proliferation and activation of the cells $(183,184)$. IDO expression is also upregulated when 
cytotoxic T-lymphocyte antigen-4 (CTLA-4) expressed on Tregs binds to CD80 and CD86 on DCs inducing tumor antigen tolerance (188). With respect to the amino acid metabolism, a competition between tumor and immune cells also exist for serine and glycine utilization to synthesize building materials for cell growth and proliferation (189). Recently, it is also suggested that cancer and T cells may share similar requirements for BCAA catabolism that regulates the mTOR signaling (77).

To generate an intracellular source of nutrients under nutrient-limiting conditions in the TME, induction of autophagy has been observed (190). Furthermore, phosphorylation and activation of a protein kinase unc-51 like kinase $1 / 2$ (Ulk1/2) by AMPK is shown to connect energy sensing with autophagy (191). If the metabolic stress is extensive then it may lead to $\mathrm{T}$ cells apoptosis (192).

In contrast to the activated effector T cells, nutrient-restrictive TME does not affect the immunosuppressive functions of Tregs (19), since Tregs preferentially utilize lipid beta-oxidation and have high levels of activated AMPK $(101,193)$ (Figure 1). Indeed, activation of AMPK signaling by treatment with metformin resulted in reduced $\mathrm{T}$ effector cells and increased Tregs $(101,194)$. Further, the metabolic products of tumor cells such as lactate and kynurenine are utilized for Treg differentiation (195). Furthermore in the TME, TGF- $\beta$ (196) and chemokines such as CCL22 (197) are present abundantly that help in the differentiation and recruitment of Tregs. Indeed, the increased presence of Tregs in the solid tumors has been associated with poor prognosis (198). Recently, it has been shown that Tregs under different inflammatory conditions change their metabolic preferences leading to modulation of their proliferation and suppressive functions (199). Foxp3 decreases Glut-1 expression and glycolysis in Tregs increasing their suppressive function, while toll-like receptor (TLR)-mediated signaling enhances the expression of Glut-1 and glycolysis resulting in a decrease in their suppressive functions (199). Reduced glucose and or elevated lactate in the TME may favor the mitochondrial oxidative metabolic pathways in Tregs promoting their suppressive functions.

\section{Immune Checkpoints}

In addition to the availability of nutrients, the capacity of $\mathrm{T}$ cells to internalize and utilize these nutrients is one of the important mechanisms regulating the $\mathrm{T}$ cell activation (91, 200, 201). Upregulation of HIF1 $\alpha, c-M y c$, and PI3K/Akt/mTOR signaling following $\mathrm{T}$ cell activation play key roles in nutrient transport by promoting expression of glycolytic and anabolic genes including nutrient transporter, Glut-1 (91, 98, 132, 134, 201-203). Immune inhibitory checkpoint signals such as CTLA-4 and programmed death receptor 1 (PD-1) and their ligands are shown to modulate one of these signaling pathways (204) (Figure 1). By sequestration of CD28 ligands, CTLA-4 can inhibit CD28-mediated activation of Akt $(86,205)$ and similarly, PD-1 can reduce c-Myc expression and PI3K/Akt/mTOR signaling (206-209) resulting in reduced Glut-1 expression, glucose uptake, and aerobic glycolysis in activated $\mathrm{T}$ cells.

PD-1 and CTLA-4 can also promote Treg cells $(210,211)$ although they are Glut-1 independent as they depend more on oxidative phosphorylation $(101,134,200)$. In fact, it has been observed that the tumor samples obtained from cancer patients comprise increased number of immunosuppressive Tregs and cytokines as well as increased expression of CTLA-4 and PD-1 and their ligands (212-214). However, as HIF1 $\alpha$ is known to interact with CTLA-4 and its receptors, HIF-mediated blockade of CTLA-4 was shown to reduce the frequency of Tregs in the tumor (215). At the same time, HIF1 $\alpha$ is associated with immune escape involving other mechanisms such as shedding of cell surface immune checkpoint regulators like MIC1 thus causing resistance of tumor cells to NK cell attack $(216,217)$. Since CTLA-4 and PD-1 are highly expressed on exhausted T cells and expression of their ligands on the tumor cells inhibits PI3K/Akt/ mTOR signaling and the upregulation of glucose and glutamine metabolism (204), T cells may not be able to reprogram their metabolism correctly thereby severely affecting their functions (Table 1). Increased expression of PD-1 on tumor-infiltrating $\mathrm{T}$ cells is also associated with reduced ability to differentiate into memory $\mathrm{T}$ cells (218). Further, many cancers express higher levels of PD-L1 or PD-L2 and have PD- $1^{+}$, exhausted T cells in their environment (219). Furthermore, co-localization of HIF $1 \alpha$ and PD-L1 in tumors has been shown to be associated with worse prognosis $(215,220)$. A link of HIF1 $\alpha$ with PD-L1 is demonstrated as HIF $1 \alpha$ is shown to bind to hypoxia-response element of the PD-L1 promoter (221). Recently, an unexpected role of PD-L1 in regulating tumor cell metabolism is reported that suggests that PD-L1 can have direct effects on cancer cells (82). Since PD-L1 promotes Akt/mTOR activation and glycolysis in tumor cells, it is suggested that checkpoint blockade therapy may correct the metabolic competition-mediated nutrient availability imbalance between $\mathrm{T}$ cells and tumor cells through a direct effect on the tumor cells (82) (Figure 1; Table 1). Since improved clinical response and survival has been obtained with checkpoint blockade antibodies, it will be useful to explore the detailed mechanisms by which these antibodies modulate Akt/ mTOR and HIF $1 \alpha$ pathways as well as their effects on the nutrient availability and immune cell metabolism in patients.

\section{Metabolic Reprograming of CAFs}

As the vasculature within a solid tumor is considered to be larger and "abnormal" compared to their normal counterparts (25), they are considered to be comparatively less efficient. Consequently, the supply of energy precursors like glucose and oxygen within the bowels of solid tumor becomes understandably limited and soon a nutrient-depleted/hypoxic environment is generated within the core of the solid tumor. Hence, with the increase in mass, the tumor cells become more and more metabolically dependent on surrounding fibroblast cells to provide them with high-energy metabolic intermediates essential to fuel the proliferation of the tumor cells. This requires an enormous metabolic remodeling in the CAFs in terms of glucose metabolism and they turn into the metabolic cattle of the tumor cells providing the later with energy precursors even at the cost of self-destruction through autophagy and mitophagy (222-224).

\section{Reprograming of Glycolytic Pathways}

The predominantly glycolytic nature of the CAFs has been well established and it is believed that the carcinoma cells "corrupt" 
the associated stromal fibroblasts and transformed them to the hyper-synthetic CAF (225). While proposing their "Reverse Warburg Hypothesis" in 2009, Lisanti and coworkers showed that the lysate of stromal cells from breast cancer patients with poor clinical outcome was associated with a considerable upregulation in the expression profile of glycolytic enzymes even under normoxic conditions (226) and lactate generated by glycolytic CAFs could be used by cancer cells through respiratory metabolism indicating that the high rate of glycolysis in CAF constitute the cornerstone of the metabolic rewiring occurring in CAF/TME (Figure 1). A loss of BRCA-1 and caveolien-1 was also reportedly observed with high glycolysis (227). However, the molecular association between a tumor suppressor gene and/or a membrane scaffolding protein with glycolytic pathway/regulatory enzymes still remains unclear. Similar metabolic shift toward glycolysis has been observed in CAFs isolated from several tumor types (228-230). An active lactate shuttle plying between the tumor cells and their associated CAFs have also been reported in several independent studies (231). In fact, a high expression of lactate transporters MCT4 and 1 and their associated protein like CD147 has been considered as a hallmark of hypoxia within TME (232-234) that shows significant correlation with tumor progression and negative clinical outcome (Figure 2). In addition to CAFs, acidic TME is also shown to modulate other stromal cells such as vascular endothelial cell inflammation and angiogenesis $(28,235,236)$.

Recently, it has been reported that downregulation of isocitrate dehydrogenase $3 \alpha$ (IDH3 $\alpha$ ) in CAFs through a TGF- $\beta$ or PDGFbased pathway might be the key factor that tips the balance toward glycolysis (237). It has also been suggested that downregulation of IDH $3 \alpha$ lowers the level of $\alpha$-ketoglutarate in the cell leading to low fumarate to succinate ratio. This imbalance in the relative abundance of TCA cycle metabolites leads to HIF1 $\alpha$ stabilization and augment glycolysis (237). HIF1 $\alpha$-mediated high expression of MCT4 has been reported in pancreatic ductal carcinomaassociated CAFs indicating an active lactate transport within tumor stroma (234).

The identification of factor/s that alters glycolysis in tumor cells remains still elusive. It has been recently reported that the biphosphatase TP53-inducible glycolysis and apoptosis regulator (TIGAR) might hold the key for this metabolic reprogramming as overexpression of TIGAR in the breast carcinoma cells boosts the ATP production and glutamine uptake in tumor cells as well as pronounced glycolytic parameters in associated CAFs (238) (Figure 1). Overexpression of TIGAR has also been found to increase proliferation, while catalytically inactive TIGAR suppresses the tumor proliferation in carcinoma cells (238), thus reemphasizing the importance of metabolic symbiosis in tumor progression.

Activation of oncogenes and tumor suppressor genes has also been implicated in metabolic remodeling of TME. For example, within growing lymphoma cells, c-Myc was found to induce the overexpression of glycolytic enzymes like LDH-A and glucose transporters like Glut-1 and thereby maintained a glycolytic flux (239). The tumor suppressor gene p53 is known to maintain the cytochrome $c$ oxidase complex through synthesis of the cytochrome $c$ oxidase 2 (SCO2) protein. Hence loss of p53, as seen in majority of cancer cells, leads to a loss of functional cytochrome c oxidase complex/mitochondrial respiration promoting a higher rate of glycolysis in cancer cells (240). Along with SCO2, loss of p53 has also been implicated in the higher expression of TIGAR thus facilitating the metabolic symbiosis in the TME (241). Since these observations were made in homogenous cultures of tumor cells in vitro, it will be interesting to see if similar mechanisms are involved in bringing about the metabolic reprogramming in $\mathrm{CAF}$ cells present within the TME.

\section{Reprograming of Glutamine-Mediated Metabolic Pathways}

In addition to reprograming of glycolytic pathways, it is suggested that tumor cells might also induce glutamine addiction in the neighboring CAFs and TAMs. TAMs isolated freshly from glioblastoma exhibit a significantly high expression of glutamine synthetase-an enzyme that can convert the intracellular glutamate to glutamine which in turn could be supplied to the tumor cells to promote the latter's proliferation (242). Glutamine deprivation has been observed to induce autophagy in tumor cells to supplement the intracellular glutamine level, while suppression of autophagy along with glutamine deprivation causes apoptotic cell death. Amelioration of these effects was observed with the addition of $\alpha$-ketoglutarate (243). This clearly indicates that in the tumor cells, like glucose, glutamine basically acts as an anaplerotic energy precursor essential for running the TCA cycle (243). In line with this, CAFs isolated from primary pancreatic ductal adenocarcinoma have been recently shown to be more susceptible toward glutamine withdrawal compared to glucose deprivation (234) (Figure 2).

Taken together, these observations suggest that within the TME while glucose-6-phosphate/pyruvate/lactate generated through glycolysis and TCA cycle intermediates like fumarate, oxaloacetate, or citrate are sequestered toward generating membrane lipids, proteins, or nucleotides for the rapidly proliferating tumor cells, ATP production greatly depends on the conversion of glutamate to $\alpha$-ketoglutarate that keeps the TCA cycle functional.

\section{Metabolic Reprograming in Cancer- Associated Adipocytes}

In recent years, a characteristic pattern of lipid deposition has been unraveled in cancer cells with the help of advanced imaging technologies like Raman scattering microscopy (69). Lipid deposition has been shown to be increased in malignant and metastatic cells of breast cancer compared to their nonmalignant counterpart (244). Lipids are a heterogeneous class of biomolecules which includes triglycerides, phospholipids, and cholesterols. While triglycerides are the principal storage molecule in animal body, the latter two are the integral component of the plasma membrane. Hence, it is reasonable to expect that proliferative cells like the tumor cells will have high deposition of lipid droplets. This aggressive deposition of lipids in tumor cells is achieved as a result of reprogramming of the lipid metabolism in 
the TME by upregulating the lipid biosynthetic machinery and/ or by promoting lipolysis in adipocytes.

The pro-tumorigenic effect of the lipid molecule is evidenced by the observation that tumor cells often metastasize in the vicinity of adipocytes or in lipid rich milieu (69). In this regard, adipokines like IL8 have been reported to provide the cytochemical cue that directs the cancer cell toward a lipid rich "soil" (245). In the vicinity of tumor cells, adipocytes undergo several functional changes supporting the tumor growth and thereby transforming into CAAs (120). These changes include increased secretion of inflammatory cytokines, proteases, etc., dedifferentiation, and delipidation leading to fewer lipid droplets in the adipocytes (120). In the last few years, CAAs have emerged as one of the factors that closely promote proliferation of tumor cells, which involves various mechanisms. Soluble factors from adipocytes have also been implicated to promote breast cancer by activating Akt through phosphorylation and upregulating genes involved in cell adhesion, matrix remodeling, and angiogenesis (246). Similarly, IGF-1 released by the human adipocytes is known to promote proliferation of MCF-7 cells. The level of IGF-1 has been found to be greatly amplified in the presence of fatty acids (247) and thus could be speculated to be the link between obesity and higher cancer risk. Fatty acids provided by the adipocytes is suggested to be the energy source that fuel the metastasis of breast cancer (248) as well as induce autophagy to promote proliferation in colon cancer (249). Also the increase in the levels of fatty acid-binding proteins (FABP) - a family of protein involved in transporting free fatty acid-in several cancers like breast, prostate, ovarian, and colorectal carcinoma [reviewed in Ref. (250)] indicate the existence of an active sequestering of fatty acid occurring between the tumor cells and CAAs. An import of free fatty acids molecules to tumor cells has been reported in several types of cancers including ovarian and prostate carcinomas $(245,251)$. Hence the presence of CD36, an integral membrane protein associated with the import of fatty acid to the interior of the cell, has often been equated with high rate of metastasis and poor prognosis $(252,253)$. However, the regulation of cross-talk between the adipocytes and the cancer cells leading to the mobilization of the fatty acid has not been elucidated so far.

Lipid molecules, in addition to being a carbon sink, are also energy-rich molecules that can support the proliferation of the tumor cells in the nutrition-deprived interior of the solid tumor. CAAs thus supply energy to cancer cells through fatty acids as cancer cells induce metabolic alterations in the CAAs like increased activity of hormone-sensitive lipases that results in increased production of fatty acids from CAAs, which is then used by cancer cells (120). Indeed, certain tumors like prostate cancer have been reported to rely less on glucose metabolism $(254,255)$ but depend mostly on FAO for energy production (256). Simultaneously, lipid biosynthesis generates $\mathrm{NADP}^{+}$which can act as an alternative acceptor for the terminal electron in electron transport chain (ETC) in the hypoxic TME (255). The $\mathrm{NADP}^{+}$can also act as a substitute for $\mathrm{NAD}^{+}$during glycolysis (70). Thus, lipid biogenesis not only ensures the sustenance of the ETC/ATP production but also maintains the high glycolytic flux in the TME.

\section{THERAPEUTIC TARGETING}

One of the important considerations in therapeutic targeting of metabolism for cancer therapy is the similar requirements for anabolic metabolism by both cancer and activated $\mathrm{T}$ cells/stromal cells. Therefore, identification of targets, metabolites, metabolic enzymes, metabolic pathways that are differentially expressed/ utilized/regulated in cancer and other stromal cells in the microenvironment is essential to avoid unintended effects on the function of stromal cells. Furthermore, this therapeutic targeting should result in increased antitumor effects of $\mathrm{T}$ effector cells, increased generation of memory cells, and reduced immunosuppressive functions of Tregs.

\section{PD-1/PD-L1/CTLA-4 Signaling}

On activation, $\mathrm{T}$ cells reprogram their metabolism to aerobic glycolysis and glutaminolysis but PD-1 signaling suppresses Akt/mTOR pathway $(204,257)$ thereby impairing the metabolic reprograming and promoting the beta-oxidation of fatty acids (214). Thus, antitumor effects of anti-PD-1 therapy will also be mediated by re-engagement of aerobic glycolysis by TILs through elevated expression of Glut-1 and glycolytic proteins (Table 1). In fact, effects of anti-PD-1 therapy were abrogated in the presence of rapamycin (257). In addition to PD-1/PD-L1 signaling-mediated effects on the TILs, PD-L1 expression on the cancer cells has been shown to mediate cell-intrinsic signaling through PI3K/Akt/ mTOR pathway leading to enhanced glycolysis in the cancer cells (82). Thus, metabolic reprograming both in cancer and immune cells is one of the important reasons for PD-1/PD-L1 blockademediated therapeutic effects (Table 1). Similar to PD-1, CTLA-4 also inhibits increased glucose metabolism following $\mathrm{T}$ cell activation, which is vital for naïve $\mathrm{T}$ cells transitioning to $\mathrm{T}$ effector cells $(204,205)$. Therefore, effects of anti-CTLA- 4 antibodies in tumor therapy could also be partially mediated due to their effects on the glycolytic metabolism (Table 1). On the other hand, non-specific pharmacological/chemical inhibitors of glycolysis like 2-deoxy-D-glucose (2-DG) could be more effective as they can modify glycolysis both in cancer cells as well as the T cells, although the consequences may not be identical in both the cell populations depending on the nature of metabolic patterns in different subsets of $\mathrm{T}$ cells. Indeed, recent studies from our laboratory have shown that a combination of systemically administered 2-DG with focal irradiation of the grafted Ehrlich ascites tumor in mice shows selective lympho-depletion coupled with differential activation of different Th cells and polarization of macrophages to M1 phenotype that strongly correlates with the local tumor control $(258,259)$ (Table 1). Since both CTLA-4 and PD-1 block glycolysis, checkpoint blockade will also enhance effector $\mathrm{T}$ cells while potentially inhibiting Tregs as they are dependent on FAO for their metabolic needs (214). Strategies that affect the signaling mediated by other surface receptors such as P2X7 and A2AR using administration of $\mathrm{NAD}^{+}$and $\mathrm{A} 2 \mathrm{AR}$ agonists, respectively, have been shown to deplete Tregs $(260,261)$.

\section{HIF1 $\alpha$ Signaling}

Hypoxia-inducible factor $1 \alpha$ controls several genes involved in glucose and lactate transport and glycolysis, such as Glut-1, MCT1, 
and MCT4 $(11,129)$. In addition, HIF1 $\alpha$ signaling also affects $\mathrm{pH}$ stabilization and angiogenesis thereby affecting the tumorigenesis and metastasis (11). Therefore, modifiers of lactate transport such as inhibition of MCT1 with alpha-cyano-4-hydroxycinnamate (CHC) has been shown to induce a switch from lactate-fueled respiration to glycolysis leading to retarded tumor growth by selectively killing hypoxic tumor cells (262) (Table 1). Such a strategy may also affect the polarization of TAMs $(115,116)$ as well as the metabolic symbiosis between CAFs and cancer cells (118) in a HIF1 $\alpha$-dependent manner. Further, inhibition of HIF1 transcription by flavopiridol (263), dimerization and synthesis by acriflavine and digoxin $(264,265)$ and induction of HIF1 degradation by trichostatin A, a histone deacetylase inhibitor (266) have been investigated as therapeutic approaches (Table 1).

Hypoxia-inducible factor $1 \alpha$ signaling plays a crucial role in regulating the immune response. However, both positive and negative regulatory effects of HIF $1 \alpha$ on $\mathrm{T}$ effector cells have been demonstrated. Although activating HIF1 $\alpha$ pathway in mouse melanoma cancer cells resulted in prevention of $\mathrm{T}$ effector cell exhaustion even in the presence of continuous antigen exposure (267), more studies are required before using HIF $1 \alpha$ activators to enhance the $\mathrm{T}$ cell-mediated responses. In addition to effects of hypoxia on immune response, hypoxia also affects angiogenesis. Anti-angiogenic therapy of cancers generally by VEGF blockade results in increased hypoxia due to metabolic reprograming that leads to tumor aggressiveness and metastasis (268). It has been shown that re-expression of semphorin $3 \mathrm{~A}$ in cancer cells improves the cancer tissue oxygenation and reduces the anti-angiogenic therapy-induced activation of HIF $1 \alpha$ leading to enhanced therapeutic effects (269).

\section{PI3K/Akt/mTOR and AMPK Pathway}

Increasing memory $\mathrm{T}$ cell prevalence has been observed with different compounds that affect PI3K/Akt/mTOR and AMPK signaling. Blocking of glycolysis by 2-DG, a hexokinase inhibitor resulted in increased AMPK activity leading to negative regulation of mTOR and Foxol and enhanced $\mathrm{CD}^{+} \mathrm{T}$ cell-mediated antitumor effects (270). Treatment with metformin also resulted in increased AMPK activation and memory $\mathrm{T}$ cell generation (271), which could be due to its effects on mTOR signaling (272) or miR33a upregulation that is responsible for downregulation of c-Myc expression (273). Rapamycin, an inhibitor of mTORC1, is shown to exert multiple effects on T cell metabolism (Table 1). It reduces glycolysis and increases lipid peroxidation through mTOR inhibition, enhances the formation of $\mathrm{T}$ memory cells (274), inhibits T-bet, a Th1-promoting transcription factor (275), and induces autophagy (276). However, since immunosuppressive effects of rapamycin have been reported (277), more investigations are required to determine the long-term antitumor effects of rapamycin. Since induction of Tregs has been observed in response to apoptotic tumor cells in an IDO-dependent manner, pharmacological inhibition of either IDO or PTEN resulted in loss of Foxo3A, a target of Akt as well as destabilization of Tregs causing rapid tumor regression (278) (Table 1). Further, several rapalogs such as temsirolimus and everolimus have been shown to exert anticancer effects (Table 1) although upregulation of PI3K/Akt pathway following treatment with rapalogs remains a matter of concern necessitating the deployment of combination strategies to inhibit this response $(28,279-281)$.

\section{Use of Metabolic Reprograming to Manipulate Metabolites and Metabolic Enzymes \\ Targeting Glucose Metabolism}

Glycolytic metabolites like PEP act as sensors for availability of glucose in the environment and can modulate the important signaling pathways regulating the effector functions of the T cells (123). Further, glycolytic enzymes such as GAPDH also have additional role as metabolic checkpoint regulators (153). Therefore, manipulating and reprograming the metabolism in $\mathrm{T}$ cells by changing the levels of these metabolites and metabolic enzymes to modulate their specialized functions can be used in adoptive cell therapy (ACT) as well as an adjunct form of immunotherapy. Indeed, overexpression of either PCK1 or PGC1 $\alpha$ in $\mathrm{T}$ cells has been shown to result in stronger antitumor responses emphasizing the potential of ACT where the expression of metabolic enzymes is modulated $(123,157)$.

Inhibition of key enzymes involved in glycolysis is one of the important strategies being considered for cancer therapy. The enzymes like hexokinase-a molecule that is involved in several pathways of carbohydrate metabolism-are emerging as one of the determinants of cancer prognosis and inhibition of hexokinase appears to be pivotal in predicting the outcome of cancer therapeutics $(282,283) .2-D G$ is an inhibitor of glycolysis that competitively inhibits hexokinase through product inhibition due to the accumulation of 2-DG-6-phosphate (2-DG-6-P), which is not metabolized further causing the metabolic block in the form of reduction in ATP from glycolysis and NADPH from PPP $(284,285)$ (Table 1). Selective sensitization of tumor cells to radiation and chemotherapeutic drugs by 2 -DG arises from differential modifications of multiple damage response pathways in tumor and normal cells. This includes depletion of energy, disturbed redox balance, and altered N-linked glycosylation leading to unfolded protein responses (UPR), collectively resulting in changes in the gene expression and phosphorylation status of proteins involved in signaling, cell cycle control, DNA repair, calcium influx, and apoptosis (286). Studies with animal tumors have shown enhanced local tumor control without significant damage to the normal cells (and tissues). Phase I-III clinical trials with a combination of 2-DG and hypofractionated radiotherapy in malignant glioma patients have shown excellent tolerance with minimal toxicity and moderate survival benefits with significantly improved quality of life (287-290).

In addition to the direct effects of 2-DG on the cancer cells, systemically administered 2-DG together with focal irradiation of the tumor has been shown to activate antitumor immunity in the peripheral blood both in terms of increase in the levels of innate and adaptive cells and decrease in B cells, where a decrease in the $\mathrm{CD}^{+}$naïve $\mathrm{T}$ cells was paralleled by the increase in $\mathrm{CD} 4^{+}-$ activated T cells (258). This was also associated with a shift from Th2 and Th17 to Th1 in the form of cytokine and switching of antibody class, which appears to be mainly due to the selective depletion of induced $\mathrm{T}$ regulatory cells $\left(\mathrm{CD} 4^{+} \mathrm{CD} 25^{+} \mathrm{FoxP} 3^{+}\right.$ 
$\left.\mathrm{CD}^{2} 9^{+} \mathrm{FR} 4^{+} \mathrm{GITR}^{+} \mathrm{CD} 127^{-}\right)$in blood, spleen, lymph node, and the tumor (258). This appears to result in the immune activation in the periphery, secondary lymphoid organs, and massive infiltration of $\mathrm{CD}^{+}, \mathrm{CD}^{+}$, and $\mathrm{NK}$ cells in the tumor, which correlates well with the tumor control (258). More recent studies have shown that 2-DG in combination with tumor irradiation polarizes splenic macrophages toward M1 type in vivo as well as in vitro (RAW 264.7) that correlated well with enhanced local tumor control (259). Clearly, effects other than glycolytic inhibition like UPR response (due to altered $\mathrm{N}$-linked glycosylation) and HIF1 $\alpha$ signaling appears to be involved in the immune activation by $2-D G$, which needs further studies to provide more insight $(258,259)$ (Table 1).

Glycolysis is associated with the activation of normal lymphocytes, i.e., the lymphocyte activation dogma (291). Interestingly, immune activation has been reported in tumor-bearing mice following systemic administration of 2-DG combined with focal irradiation of the tumor, which appears to be out of tune with the dogma, although lympho-depletion was seen 1 day after the administration (258). Interestingly, the tumor response appears to be determined by the changes in the immune status seen soon (1 day) after the treatment, suggesting that these indicators of alterations in the immune status can also serve as surrogate markers of tumor response to the combined treatment involving 2-DG.

Glycolytic inhibitors other than 2-DG have also been evaluated for their potential to influence the therapeutic response. For example, complete remission has been observed in a patient with relapsed non-Hodgkin's lymphoma following treatment with sodium dichloroacetate (DCA) that targets PDK1 thereby reducing lactate production (292) (Table 1). Further, 6-aminonicotinamide (6-AN) has been used to inhibit the glycolytic shunt into PPP by inhibiting G6PD $(293,294)$ (Table 1). A higher degree of radiosensitization has been reported by a combination of 2-DG and 6-AN in both cancer cells and in vivo in Ehrlich ascites tumor-bearing mice (295-297). PFK-and its regulatory molecules-are also of particular interest as plausible targets for cancer therapy. PFKFB3 is known to synthesize fructose 2,6-bisphosphate (F2,6P2) which acts as an allosteric activator for PFK-1. Hence, small molecule inhibitors of PFKFB3, like PFK15 (1-(4-pyridinyl)-3-(2-quinolinyl)-2-propen-1-one) or epigallocatechin-3-gallate (EGCG) $(298,299)$ are known to considerably suppress tumor cell proliferation (Table 1). Some other anticancer agents like curcumin are also known to stall cancer progression by suppressing the PFK, hexokinase, Glut- 4 expression both at mRNA and protein levels (300) (Table 1). Inhibition of PFKFB3 with pharmacological inhibitors like 3-(3-pyridinyl)1-(4-pyridinyl)-2-propen-1-one (3-PO) in endothelial cells also leads to the suppression of the enhanced glycolysis $(298,301)$ (Table 1). Though the detailed molecular mechanism is unknown, it is assumed that this leads to improved tumor vasculatures through better adhesion of the pericytes (301). Blocking glycolysis in endothelial cells is thus also emerging as a novel therapeutic approach in cancer therapy. Pharmacological inhibitors of hexokinase and PFKFB3 like 2-DG and PFK15 have been successful in causing cytotoxicity in endothelial cells showing promise as therapeutic agents for cancer (119) (Table 1). Another metabolic analog that interferes with glycolysis and thereby tumor progression is 3-bromopyruvate (3-BP). 3 - $\mathrm{BP}$ is known to suppress the expression of lactate transporter, MCT1 (302) as well as interfere with the activity of hexokinase (303) (Table 1). Taken together, in cases of multiple myeloma, treatment with 3-BP reduced the ATP level to $10 \%$ of untreated cells within $1 \mathrm{~h}$ leading to cytotoxicity (302). In addition to 3-BP, AZD3965, an inhibitor of MCT 1/2 targeting the transfer of lactate between cancer and cancer/stromal cells (Table 1) has been developed and is being tested for clinical efficacy (304). Another hexokinase and MCT1 inhibitor, Lonidamine has shown promising selective anticancer effects and has reached phase II of clinical trials (Table 1) (305-307). Similarly, caulerpin, a secondary metabolite, is presently being speculated for its anticancer property as its long-term application was found to interfere with the glycolytic machinery through AMPK pathway (308) (Table 1).

Although the conclusive picture of the signaling cascade that regulate the molecular remodeling in CAFs is yet to emerge, it will be interesting to speculate the candidature of molecules like TGF$\beta$ and c-Myc as potential drug targets (Table 1). TGF- $\beta$ reportedly suppresses the TCA cycle enzyme isocitrate dehydrogenase (237) through a TGF- $\beta /$ PDGF-mediated pathway thereby promoting glycolytic metabolism in CAF. Similarly, high activation of c-Myc promotes the expression of LDH-A and Glut-1 that are essential in maintaining the glycolytic flux (239).

\section{Targeting Amino Acid Metabolism}

The catabolism of L-arginine and tryptophan plays a significant role in tumor progression and immunity. Enhanced intra-tumoral RNS production due to increased metabolism of arginine in the TME induces CCL2 chemokine nitration and hinders T cell infiltration (309). It was reported that preconditioning of the TME with novel drugs that inhibit CCL2 modification facilitates CTL invasion of the tumor, suggesting their effectiveness in cancer immunotherapy (309).

Exhausted and antigen-tolerant $\mathrm{T}$ cells might be reactivated using IDO inhibitors resulting in increased tryptophan levels. This may be more beneficial in cancer therapy than increasing glycolysis as differential effects on immune cells could be obtained since glycolytic metabolic pathways are used both by cancer and $\mathrm{T}$ cells for their growth and survival. Two of the IDO inhibitors 1-methyl-tryptophan (1-MT) (310) and INCB024360 (311) have shown antitumor activity in mice tumor models due to increased $\mathrm{T}$ cell proliferation (Table 1). Downregulation of IDO has been observed with imatinib, a Bcr-Abl tyrosine kinase inhibitor in gastrointestinal tumors that resulted in the activation of $\mathrm{CD}^{+} \mathrm{T}$ cells and induced Treg cell apoptosis leading to enhanced antitumor effects (312) (Table 1). Imatinib could also inhibit Lck-mediated TCR signaling $(313,314)$ that is important for maximum glucose uptake through Glut-1 (86). This may lead to negative effects on $\mathrm{T}$ cell transition and therefore detrimental effects on antitumor immune responses.

\section{Targeting Lipid Metabolism}

Unlike T effector cells, Tregs depend on lipid metabolism for their differentiation and this provides an opportunity to differentially target these cells by using lipid oxidation blockers. An important role of FAO key enzyme, carnitine palmitoyl transferase la 
(CPT-1a) has been demonstrated in cancer cell survival in conditions of energy stress as it rewires the cancer cell metabolism $(315,316)$. Treatment of Tregs with etomoxir, a CPT-1a inhibitor resulted in differential suppression of Treg generation but not Th1 cells (101) making etomoxir a promising metabolic modulator for cancer therapy (Table 1). 3-hydroxy-3-methylglutaryl-CoA reductase (HMGCR), a rate-limiting enzyme for the synthesis of cholesterol and isoprenoid lipids has been targeted using a general lipid-synthesis inhibitor, 25-hydroxycholesterol, and drugs such as simvastatin, atorvastatin, and lovastatin to impair the activity of Tregs as HMGCR is needed for proliferation of Tregs (317) (Table 1).

As CAAs provide a source of energy to cancer cells in the form of fatty acids, preventing induction of CAA phenotype provides another promising therapeutic strategy. Several thiazolidinediones (troglitazone, rosiglitazone, and pioglitazone) that are ligands for PPAR $\gamma$, which regulates the terminal differentiation of adipocytes (318), have been shown to inhibit the dedifferentiation of adipocytes to CAA (319) (Table 1). However, some of the thiazolidinediones are associated with cardiovascular side effects (120) and hence strategies that block cancer cells from using energy supplied by the CAAs have been developed using FABP4 inhibitors (245) and metformin (Table 1). Interestingly, metformin plays dual role in cancer therapy by inhibiting both the use of CAA-supplied energy by cancer cells as well as cancer cell-induced metabolic changes in the CAFs. Metformin has been found to block adipocyte-mediated lipid accumulation in ovarian cancer cells (320) and reverses the CAF phenotype induced by cancer cells by restoring caveolin expression in the fibroblasts (321).

\section{Targeting Acidic TME}

The acidic TME that alters tumor metabolism has been targeted with systemic buffer therapy using buffers such as lysine, sodium bicarbonate, or 2-imidazole-1-yl-3-ethoxycarbonylpropionicacid (IEPA) (Table 1) to alkalize the TME leading to reduced tumor growth and metastasis (322-324) and to increase the activity of some drugs that otherwise remain inactive in acidic environments $(325,326)$. Further, proton pump inhibition to manipulate tumor $\mathrm{pH}$ and increase the intracellular acidity has also been employed as a therapeutic strategy. Bafilomycin A1 (327) and archazolid (328), V-ATPase proton pump inhibitors showed anticancer activity in several types of cancers. Therapeutic effects of several other proton pump inhibitors such as omeprazole, esomeprazole, rabeprazole, pantoprazole, and lansoprazole (Table 1) have been investigated suggesting the potential of these inhibitors in cancer therapy (329). Another attractive target of acidic cancer cells is CAIX that is overexpressed in these cells due to extracellular acidosis (330). Several inhibitors such as sulfonamides, sulfamates, and sulfamides (Table 1) have been developed that bind to the catalytic site of the enzyme (331). In vivo efficacy of these compounds is currently under investigation; however, a significant reduction in tumor growth and metastasis has been observed in a mammary tumor model in mice with novel CAIX inhibitors (332). Since acidic TME modulates the activation of proton-sensing G-protein-coupled receptors (333), an agonist of GPR68 (Table 1) has been investigated and has shown inhibitory effects in malignant astrocyte proliferation. However, further understanding of the molecular signaling and mechanisms of how these receptors alter tumor metabolism is essential to develop novel small molecules for cancer therapy.

\section{CONCLUSION AND FUTURE DIRECTION}

Although insight into the intricate nature of metabolic cooperation between the tumor cells and various host cells that it interacts within the microenvironment are emerging at the present, their potential as therapeutic targets is already indicated by the encouraging results from the studies with modifiers of lactate transport (MCT1) $(17,262)$. More recent studies showing the immune suppressive potential of lactic acid (3) emphasizes the importance of this metabolite that has an important role in the metabolic crosstalk between cancer cells and fibroblasts as well as the immune cells. Similarly, the dependence of cancer cells on the CAF for glutamine uptake (334) as well as support provided by the endothelial cells for their growth (119) highlights the importance of metabolic cooperation that can be used as a target for developing therapies (72). Further, the revelations on the contributions of immune modulation by the glycolytic inhibitor 2 -DG to radiosensitization of tumors $(258,259)$ and its potential to impair the tumorigenesis (335) lend support to the proposition of targeting host-tumor interactions by metabolic modifiers for enhancing therapeutic gain. Furthermore, development of therapies that enhance the responses mediated by effector and memory $\mathrm{T}$ cells while reducing the suppressive functions of Tregs hold significant potential for cancer immunotherapy. Several therapeutic strategies for regulating Treg cell metabolism have been developed [reviewed in Ref. (336)]. Indeed, many of the currently employed therapeutic modalities target the metabolic pathways or the signaling cascades that govern them (Figures 1 and 2; Table 1). However, the metabolic cooperation as well as competition that set the metabolic fitness of different types of cells present in the TME needs further investigations to achieve better clinical outcomes. Therefore, while using engineered $\mathrm{T}$ cells during ACT or chimeric antigen receptor (CAR) T cell therapies, it is important to consider that limiting nutrients and other conditions in the TME will influence the effectiveness of these strategies. In addition, the cells of the innate immune system may recognize signals released from the cancer cells thereby supporting carcinogenesis. Pattern recognition receptors (PRRs) present on the surfaces of macrophages and other cells recognize different types of obnoxious stimuli present in their immediate vicinity and activate intracellular signaling cascades, which generally leads to the induction of pro-inflammatory response through upregulation of several genes $(337,338)$. There are several families of PRRs; however, the best characterized are the TLRs and the NOD-like receptors (NLRs). The ability of damage-associated molecular patterns (DAMP) released from dying cells (apoptotic and necrotic) has been widely implicated in tumorigenesis beyond pathogen-driven neoplasms (338) and may facilitate the interaction of tumor cells and cells of the immune network. Understanding the nature of metabolic reprograming in PRR-mediated tumor progression is required for developing therapeutic strategies that specifically target this 
aspect of the TME. Although anticancer therapies targeting the metabolic reprogramming have not been completely developed so far, increasing knowledge about this phenotype coupled with the insights gained about the TME is expected to result in the development of novel anticancer therapies in the near future.

\section{REFERENCES}

1. Warburg O. The Metabolism of Tumors. London: Constable and Co. (1930).

2. Martinez-Outschoorn U, Sotgia F, Lisanti MP. Tumor microenvironment and metabolic synergy in breast cancers: critical importance of mitochondrial fuels and function. Semin Oncol (2014) 41:195-216. doi:10.1053/j.seminoncol. 2014.03.002

3. Choi SY, Collins CC, Gout PW, Wang Y. Cancer-generated lactic acid: a regulatory, immunosuppressive metabolite? J Pathol (2013) 230:350-5. doi:10.1002/ path.4218

4. Pearce EL, Pearce EJ. Metabolic pathways in immune cell activation and quiescence. Immunity (2013) 38:633-43. doi:10.1016/j.immuni.2013.04.005

5. Buck MD, O'Sullivan D, Pearce EL. T cell metabolism drives immunity. J Exp Med (2015) 212:1345-60. doi:10.1084/jem.20151159

6. O'Sullivan D, Pearce EL. Targeting T cell metabolism for therapy. Trends Immunol (2015) 36:71-80. doi:10.1016/j.it.2014.12.004

7. O'Sullivan D, van der Windt GJ, Huang SC, Curtis JD, Chang CH, Buck MD, et al. Memory CD8(+) T cells use cell-intrinsic lipolysis to support the metabolic programming necessary for development. Immunity (2014) 41:75-88. doi:10.1016/j.immuni.2014.06.005

8. Lunt SJ, Chaudary N, Hill RP. The tumor microenvironment and metastatic disease. Clin Exp Metastasis (2009) 26:19-34. doi:10.1007/s10585-008-9182-2

9. Cairns RA, Harris IS, Mak TW. Regulation of cancer cell metabolism. Nat Rev Cancer (2011) 11:85-95. doi:10.1038/nrc2981

10. Pavlides S, Vera I, Gandara R, Sneddon S, Pestell RG, Mercier I, et al. Warburg meets autophagy: cancer-associated fibroblasts accelerate tumor growth and metastasis via oxidative stress, mitophagy, and aerobic glycolysis. Antioxid Redox Signal (2012) 16:1264-84. doi:10.1089/ars.2011.4243

11. Eckert AW, Wickenhauser C, Salins PC, Kappler M, Bukur J, Seliger B. Clinical relevance of the tumor microenvironment and immune escape of oral squamous cell carcinoma. J Transl Med (2016) 14:85. doi:10.1186/s12967016-0828-6

12. Arora A, Singh S, Bhatt AN, Pandey S, Sandhir R, Dwarakanath BS. Interplay between metabolism and oncogenic process: role of microRNAs. Transl Oncogenomics (2015) 7:11-27. doi:10.4137/TOG.S29652

13. Kouidhi S, Noman MZ, Kieda C, Elgaaied AB, Chouaib S. Intrinsic and tumor microenvironment-induced metabolism adaptations of $\mathrm{T}$ cells and impact on their differentiation and function. Front Immunol (2016) 7:114. doi:10.3389/ fimmu.2016.00114

14. Wu W, Zhao S. Metabolic changes in cancer: beyond the Warburg effect. Acta Biochim Biophys Sin (Shanghai) (2013) 45:18-26. doi:10.1093/abbs/gms104

15. Wang T, Liu G, Wang R. The intercellular metabolic interplay between tumor and immune cells. Front Immunol(2014) 5:358. doi:10.3389/fimmu.2014.00358

16. Siska PJ, Rathmell JC. T cell metabolic fitness in antitumor immunity. Trends Immunol (2015) 36:257-64. doi:10.1016/j.it.2015.02.007

17. Pisarsky L, Bill R, Fagiani E, Dimeloe S, Goosen RW, Hagmann J, et al. Targeting metabolic symbiosis to overcome resistance to anti-angiogenic therapy. Cell Rep (2016) 15:1161-74. doi:10.1016/j.celrep.2016.04.028

18. Nakajima EC, Van Houten B. Metabolic symbiosis in cancer: refocusing the Warburg lens. Mol Carcinog (2013) 52:329-37. doi:10.1002/mc.21863

19. Molon B, Cali B, Viola A. T cells and cancer: how metabolism shapes immunity. Front Immunol (2016) 7:20. doi:10.3389/fimmu.2016.00020

20. Mockler MB, Conroy MJ, Lysaght J. Targeting T cell immunometabolism for cancer immunotherapy; understanding the impact of the tumor microenvironment. Front Oncol (2014) 4:107. doi:10.3389/fonc.2014.00107

21. Kalluri R, Zeisberg M. Fibroblasts in cancer. Nat Rev Cancer (2006) 6:392-401. doi: $10.1038 / \mathrm{nrc} 1877$

22. Pietras K, Ostman A. Hallmarks of cancer: interactions with the tumor stroma. Exp Cell Res (2010) 316:1324-31. doi:10.1016/j.yexcr.2010.02.045

23. Amatangelo MD, Bassi DE, Klein-Szanto AJ, Cukierman E. Stromaderived three-dimensional matrices are necessary and sufficient to

\section{AUTHOR CONTRIBUTIONS}

All three authors jointly developed the structure and arguments for the paper, prepared the manuscript, reviewed, and approved the final manuscript.

promote desmoplastic differentiation of normal fibroblasts. Am JPathol (2005) 167:475-88. doi:10.1016/S0002-9440(10)62991-4

24. Siemann DW. The unique characteristics of tumor vasculature and preclinical evidence for its selective disruption by tumor-vascular disrupting agents. Cancer Treat Rev (2011) 37:63-74. doi:10.1016/j.ctrv.2010.05.001

25. Nagy JA, Chang SH, Dvorak AM, Dvorak HF. Why are tumour blood vessels abnormal and why is it important to know? Br J Cancer (2009) 100:865-9. doi:10.1038/sj.bjc.6604929

26. Chiche J, Brahimi-Horn MC, Pouyssegur J. Tumour hypoxia induces a metabolic shift causing acidosis: a common feature in cancer. J Cell Mol Med (2010) 14:771-94. doi:10.1111/j.1582-4934.2009.00994.x

27. Peppicelli S, Andreucci E, Ruzzolini J, Margheri F, Laurenzana A, Bianchini F, et al. Acidity of microenvironment as a further driver of tumor metabolic reprogramming. J Clin Cell Immunol (2017) 8:485-9. doi:10.4172/2155-9899. 1000485

28. Justus CR, Sanderlin EJ, Yang LV. Molecular connections between cancer cell metabolism and the tumor microenvironment. Int J Mol Sci (2015) 16:11055-86. doi:10.3390/ijms160511055

29. Chen JL, Lucas JE, Schroeder T, Mori S, Wu J, Nevins J, et al. The genomic analysis of lactic acidosis and acidosis response in human cancers. PLoS Genet (2008) 4:e1000293. doi:10.1371/journal.pgen.1000293

30. Xie J, Wu H, Dai C, Pan Q, Ding Z, Hu D, et al. Beyond Warburg effect - dual metabolic nature of cancer cells. Sci Rep (2014) 4:4927. doi:10.1038/srep04927

31. DeBerardinis RJ, Lum JJ, Hatzivassiliou G, Thompson CB. The biology of cancer: metabolic reprogramming fuels cell growth and proliferation. Cell Metab (2008) 7:11-20. doi:10.1016/j.cmet.2007.10.002

32. Eigenbrodt E, Reinacher M, Scheefers-Borchel U, Scheefers H, Friis R. Double role for pyruvate kinase type M2 in the expansion of phosphometabolite pools found in tumor cells. Crit Rev Oncog (1992) 3:91-115.

33. Warburg O. On the origin of cancer cells. Science (1956) 123:309-14. doi:10.1126/science.123.3191.309

34. Bost F, Decoux-Poullot AG, Tanti JF, Clavel S. Energy disruptors: rising stars in anticancer therapy? Oncogenesis (2016) 5:e188. doi:10.1038/oncsis. 2015.46

35. Slaninova V, Krafcikova M, Perez-Gomez R, Steffal P, Trantirek L, Bray SJ, et al. Notch stimulates growth by direct regulation of genes involved in the control of glycolysis and the tricarboxylic acid cycle. Open Biol (2016) 6:150155 doi:10.1098/rsob.150155

36. Dang CV, O’Donnell KA, Zeller KI, Nguyen T, Osthus RC, Li F. The c-Myc target gene network. Semin Cancer Biol (2006) 16:253-64. doi:10.1016/j. semcancer.2006.07.014

37. Wilde BR, Ayer DE. Interactions between Myc and MondoA transcription factors in metabolism and tumourigenesis. Br J Cancer (2015) 113:1529-33. doi:10.1038/bjc.2015.360

38. Yeung SJ, Pan J, Lee MH. Roles of p53, MYC and HIF-1 in regulating glycolysis - the seventh hallmark of cancer. Cell Mol Life Sci (2008) 65:3981-99. doi:10.1007/s00018-008-8224-x

39. Ke Q, Costa M. Hypoxia-inducible factor-1 (HIF-1). Mol Pharmacol (2006) 70:1469-80. doi:10.1124/mol.106.027029

40. Papandreou I, Cairns RA, Fontana L, Lim AL, Denko NC. HIF-1 mediates adaptation to hypoxia by actively downregulating mitochondrial oxygen consumption. Cell Metab (2006) 3:187-97. doi:10.1016/j.cmet.2006.01.012

41. Kim JW, Tchernyshyov I, Semenza GL, Dang CV. HIF-1-mediated expression of pyruvate dehydrogenase kinase: a metabolic switch required for cellular adaptation to hypoxia. Cell Metab (2006) 3:177-85. doi:10.1016/j.cmet. 2006.02.002

42. Semenza GL. Regulation of cancer cell metabolism by hypoxia-inducible factor 1. Semin Cancer Biol (2009) 19:12-6. doi:10.1016/j.semcancer.2008.11.009

43. Swietach P, Hulikova A, Vaughan-Jones RD, Harris AL. New insights into the physiological role of carbonic anhydrase IX in tumour $\mathrm{pH}$ regulation. Oncogene (2010) 29:6509-21. doi:10.1038/onc.2010.455 
44. Zhang H, Bosch-Marce M, Shimoda LA, Tan YS, Baek JH, Wesley JB, et al. Mitochondrial autophagy is an HIF-1-dependent adaptive metabolic response to hypoxia. J Biol Chem (2008) 283:10892-903. doi:10.1074/jbc.M800102200

45. Fukuda R, Zhang H, Kim JW, Shimoda L, Dang CV, Semenza GL. HIF-1 regulates cytochrome oxidase subunits to optimize efficiency of respiration in hypoxic cells. Cell (2007) 129:111-22. doi:10.1016/j.cell.2007.01.047

46. Guertin DA, Sabatini DM. Defining the role of mTOR in cancer. Cancer Cell (2007) 12:9-22. doi:10.1016/j.ccr.2007.05.008

47. Browne GJ, Proud CG. A novel mTOR-regulated phosphorylation site in elongation factor 2 kinase modulates the activity of the kinase and its binding to calmodulin. Mol Cell Biol (2004) 24:2986-97. doi:10.1128/MCB.24.7.29862997.2004

48. Vaupel P, Kallinowski F, Okunieff P. Blood flow, oxygen and nutrient supply, and metabolic microenvironment of human tumors: a review. Cancer Res (1989) 49:6449-65.

49. Vaupel P. Tumor microenvironmental physiology and its implications for radiation oncology. Semin Radiat Oncol (2004) 14:198-206. doi:10.1016/j. semradonc.2004.04.008

50. Helmlinger G, Sckell A, Dellian M, Forbes NS, Jain RK. Acid production in glycolysis-impaired tumors provides new insights into tumor metabolism. Clin Cancer Res (2002) 8:1284-91.

51. Williams AC, Collard TJ, Paraskeva C. An acidic environment leads to p53 dependent induction of apoptosis in human adenoma and carcinoma cell lines: implications for clonal selection during colorectal carcinogenesis. Oncogene (1999) 18:3199-204. doi:10.1038/sj.onc.1202660

52. Putney LK, Barber DL. Na-H exchange-dependent increase in intracellular pH times G2/M entry and transition. J Biol Chem (2003) 278:44645-9. doi:10.1074/jbc.M308099200

53. Morita T. Low pH leads to sister-chromatid exchanges and chromosomal aberrations, and its clastogenicity is S-dependent. Mutat Res (1995) 334:301-8. doi:10.1016/0165-1161(95)90067-5

54. Morita T, Nagaki T, Fukuda I, Okumura K. Clastogenicity of low pH to various cultured mammalian cells. Mutat Res (1992) 268:297-305. doi:10.1016/ 0027-5107(92)90235-T

55. Snabaitis AK, Cuello F, Avkiran M. Protein kinase B/Akt phosphorylates and inhibits the cardiac Na+/H+ exchanger NHE1. Circ Res (2008) 103:881-90. doi:10.1161/CIRCRESAHA.108.175877

56. Meima ME, Webb BA, Witkowska HE, Barber DL. The sodium-hydrogen exchanger NHE1 is an Akt substrate necessary for actin filament reorganization by growth factors. J Biol Chem (2009) 284:26666-75. doi:10.1074/jbc. M109.019448

57. Jensen DH, Therkildsen MH, Dabelsteen E. A reverse Warburg metabolism in oral squamous cell carcinoma is not dependent upon myofibroblasts. J Oral Pathol Med (2015) 44:714-21. doi:10.1111/jop.12297

58. Starska K, Forma E, Jozwiak P, Brys M, Lewy-Trenda I, Brzezinska-Blaszczyk E, et al. Gene and protein expression of glucose transporter 1 and glucose transporter 3 in human laryngeal cancer-the relationship with regulatory hypoxia-inducible factor-1alpha expression, tumor invasiveness, and patient prognosis. Tumour Biol (2015) 36:2309-21. doi:10.1007/s13277-014-2838-4

59. Eckert AW, Lautner MH, Schutze A, Taubert H, Schubert J, Bilkenroth U. Coexpression of hypoxia-inducible factor-1alpha and glucose transporter-1 is associated with poor prognosis in oral squamous cell carcinoma patients. Histopathology (2011) 58:1136-47. doi:10.1111/j.1365-2559.2011.03806.x

60. Dwarakanath B, Jain V. Targeting glucose metabolism with 2-deoxy-Dglucose for improving cancer therapy. Future Oncol (2009) 5:581-5. doi: $10.2217 /$ fon. 09.44

61. Gambhir SS. Molecular imaging of cancer with positron emission tomography. Nat Rev Cancer (2002) 2:683-93. doi:10.1038/nrc882

62. Kim JW, Dang CV. Cancer's molecular sweet tooth and the Warburg effect. Cancer Res (2006) 66:8927-30. doi:10.1158/0008-5472.CAN-06-1501

63. Cao X, Fang L, Gibbs S, Huang Y, Dai Z, Wen P, et al. Glucose uptake inhibitor sensitizes cancer cells to daunorubicin and overcomes drug resistance in hypoxia. Cancer Chemother Pharmacol (2007) 59:495-505. doi:10.1007/ s00280-006-0291-9

64. Xu RH, Pelicano H, Zhou Y, Carew JS, Feng L, Bhalla KN, et al. Inhibition of glycolysis in cancer cells: a novel strategy to overcome drug resistance associated with mitochondrial respiratory defect and hypoxia. Cancer Res (2005) 65:613-21.
65. Bhatt AN, Chauhan A, Khanna S, Rai Y, Singh S, Soni R, et al. Transient elevation of glycolysis confers radio-resistance by facilitating DNA repair in cells. BMC Cancer (2015) 15:335. doi:10.1186/s12885-015-1368-9

66. Kuo W, Lin J, Tang TK. Human glucose-6-phosphate dehydrogenase (G6PD) gene transforms NIH 3T3 cells and induces tumors in nude mice. Int J Cancer (2000) 85:857-64. doi:10.1002/(SICI)1097-0215(20000315)85:6 $<857::$ AID-IJC20>3.3.CO;2-L

67. Ramos-Montoya A, Lee WN, Bassilian S, Lim S, Trebukhina RV, Kazhyna MV, et al. Pentose phosphate cycle oxidative and nonoxidative balance: a new vulnerable target for overcoming drug resistance in cancer. Int J Cancer (2006) 119:2733-41. doi:10.1002/ijc.22227

68. Zanuy M, Ramos-Montoya A, Villacanas O, Canela N, Miranda A, Aguilar E, et al. Cyclin-dependent kinases 4 and 6 control tumor progression and direct glucose oxidation in the pentose cycle. Metabolomics (2012) 8:454-64. doi:10.1007/s11306-011-0328-x

69. Beloribi-Djefaflia S, Vasseur S, Guillaumond F. Lipid metabolic reprogramming in cancer cells. Oncogenesis (2016) 5:e189. doi:10.1038/oncsis.2015.49

70. Santos CR, Schulze A. Lipid metabolism in cancer. FEBS J (2012) 279:2610-23. doi:10.1111/j.1742-4658.2012.08644.x

71. Hensley CT, Wasti AT, DeBerardinis RJ. Glutamine and cancer: cell biology, physiology, and clinical opportunities. J Clin Invest (2013) 123:3678-84. doi:10.1172/JCI69600

72. Tajan M, Vousden KH. The Quid Pro Quo of the tumor/stromal interaction. Cell Metab (2016) 24:645-6. doi:10.1016/j.cmet.2016.10.017

73. Wang Q, Hardie RA, Hoy AJ, van Geldermalsen M, Gao D, Fazli L, et al. Targeting ASCT2-mediated glutamine uptake blocks prostate cancer growth and tumour development. J Pathol (2015) 236:278-89. doi:10.1002/path.4518

74. van Geldermalsen M, Wang Q, Nagarajah R, Marshall AD, Thoeng A, Gao D, et al. ASCT2/SLC1A5 controls glutamine uptake and tumour growth in triple-negative basal-like breast cancer. Oncogene (2016) 35:3201-8. doi:10.1038/onc.2015.381

75. Lamonte G, Tang X, Chen JL, Wu J, Ding CK, Keenan MM, et al. Acidosis induces reprogramming of cellular metabolism to mitigate oxidative stress. Cancer Metab (2013) 1:23. doi:10.1186/2049-3002-1-23

76. Perez-Escuredo J, Dadhich RK, Dhup S, Cacace A, Van Hee VF, De Saedeleer CJ, et al. Lactate promotes glutamine uptake and metabolism in oxidative cancer cells. Cell Cycle (2016) 15:72-83. doi:10.1080/15384101.2015.1120930

77. Ananieva E. Targeting amino acid metabolism in cancer growth and antitumor immune response. World J Biol Chem (2015) 6:281-9. doi:10.4331/ wjbc.v6.i4.281

78. Pearce EL, Poffenberger MC, Chang CH, Jones RG. Fueling immunity: insights into metabolism and lymphocyte function. Science (2013) 342:1242454. doi:10.1126/science.1242454

79. Greiner EF, Guppy M, Brand K. Glucose is essential for proliferation and the glycolytic enzyme induction that provokes a transition to glycolytic energy production. J Biol Chem (1994) 269:31484-90.

80. Carr EL, Kelman A, Wu GS, Gopaul R, Senkevitch E, Aghvanyan A, et al. Glutamine uptake and metabolism are coordinately regulated by ERK/MAPK during T lymphocyte activation. J Immunol (2010) 185:1037-44. doi:10.4049/ jimmunol.0903586

81. Vesely MD, Schreiber RD. Cancer immunoediting: antigens, mechanisms, and implications to cancer immunotherapy. Ann N Y Acad Sci (2013) 1284:1-5. doi:10.1111/nyas.12105

82. Chang CH, Qiu J, O'Sullivan D, Buck MD, Noguchi T, Curtis JD, et al. Metabolic competition in the tumor microenvironment is a driver of cancer progression. Cell (2015) 162:1229-41. doi:10.1016/j.cell.2015.08.016

83. Crespo J, Sun H, Welling TH, Tian Z, Zou W. T cell anergy, exhaustion, senescence, and stemness in the tumor microenvironment. Curr Opin Immunol (2013) 25:214-21. doi:10.1016/j.coi.2012.12.003

84. Guppy M, Greiner E, Brand K. The role of the Crabtree effect and an endogenous fuel in the energy metabolism of resting and proliferating thymocytes. Eur J Biochem (1993) 212:95-9. doi:10.1111/j.1432-1033.1993. tb17637.x

85. Marelli-Berg FM, Fu H, Mauro C. Molecular mechanisms of metabolic reprogramming in proliferating cells: implications for T-cell-mediated immunity. Immunology (2012) 136:363-9. doi:10.1111/j.1365-2567.2012.03583.x

86. Jacobs SR, Herman CE, Maciver NJ, Wofford JA, Wieman HL, Hammen JJ, et al. Glucose uptake is limiting in $\mathrm{T}$ cell activation and requires 
CD28-mediated Akt-dependent and independent pathways. J Immunol (2008) 180:4476-86. doi:10.4049/jimmunol.180.7.4476

87. Fox CJ, Hammerman PS, Thompson CB. Fuel feeds function: energy metabolism and the T-cell response. Nat Rev Immunol (2005) 5:844-52. doi:10.1038/ nri1710

88. Bradley LM, Haynes L, Swain SL. IL-7: maintaining T-cell memory and achieving homeostasis. Trends Immunol (2005) 26:172-6. doi:10.1016/j. it.2005.01.004

89. Hammerman PS, Fox CJ, Thompson CB. Beginnings of a signal-transduction pathway for bioenergetic control of cell survival. Trends Biochem Sci (2004) 29:586-92. doi:10.1016/j.tibs.2004.09.008

90. Plas DR, Rathmell JC, Thompson CB. Homeostatic control of lymphocyte survival: potential origins and implications. Nat Immunol (2002) 3:515-21. doi:10.1038/ni0602-515

91. Nakaya M, Xiao Y, Zhou X, Chang JH, Chang M, Cheng X, et al. Inflammatory $\mathrm{T}$ cell responses rely on amino acid transporter ASCT2 facilitation of glutamine uptake and mTORC1 kinase activation. Immunity (2014) 40:692-705. doi:10.1016/j.immuni.2014.04.007

92. Rodriguez PC, Zea AH, Culotta KS, Zabaleta J, Ochoa JB, Ochoa AC. Regulation of T cell receptor CD3zeta chain expression by L-arginine. J Biol Chem (2002) 277:21123-9. doi:10.1074/jbc.M110675200

93. Rodriguez PC, Quiceno DG, Ochoa AC. L-arginine availability regulates T-lymphocyte cell-cycle progression. Blood (2007) 109:1568-73. doi:10.1182/ blood-2006-06-031856

94. Chen L, Flies DB. Molecular mechanisms of T cell co-stimulation and coinhibition. Nat Rev Immunol (2013) 13:227-42. doi:10.1038/nri3405

95. Frauwirth KA, Thompson CB. Regulation of T lymphocyte metabolism. J Immunol (2004) 172:4661-5. doi:10.4049/jimmunol.172.8.4661

96. Dan HC, Ebbs A, Pasparakis M, Van Dyke T, Basseres DS, Baldwin AS. Akt-dependent activation of mTORC1 complex involves phosphorylation of mTOR (mammalian target of rapamycin) by IkappaB kinase alpha (IKKalpha). J Biol Chem (2014) 289:25227-40. doi:10.1074/jbc.M114.554881

97. Morita M, Gravel SP, Hulea L, Larsson O, Pollak M, St-Pierre J, et al. mTOR coordinates protein synthesis, mitochondrial activity and proliferation. Cell Cycle (2015) 14:473-80. doi:10.4161/15384101.2014.991572

98. Wang R, Dillon CP, Shi LZ, Milasta S, Carter R, Finkelstein D, et al. The transcription factor Myc controls metabolic reprogramming upon $\mathrm{T}$ lymphocyte activation. Immunity (2011) 35:871-82. doi:10.1016/j.immuni.2011. 09.021

99. Peter C, Waldmann H, Cobbold SP. mTOR signalling and metabolic regulation of T cell differentiation. Curr Opin Immunol (2010) 22:655-61. doi:10.1016/j.coi.2010.08.010

100. Powell JD, Delgoffe GM. The mammalian target of rapamycin: linking T cell differentiation, function, and metabolism. Immunity (2010) 33:301-11. doi:10.1016/j.immuni.2010.09.002

101. Michalek RD, Gerriets VA, Jacobs SR, Macintyre AN, MacIver NJ, Mason EF, et al. Cutting edge: distinct glycolytic and lipid oxidative metabolic programs are essential for effector and regulatory CD4+ T cell subsets. J Immunol (2011) 186:3299-303. doi:10.4049/jimmunol.1003613

102. Rubtsov YP, Niec RE, Josefowicz S, Li L, Darce J, Mathis D, et al. Stability of the regulatory T cell lineage in vivo. Science (2010) 329:1667-71. doi:10.1126/ science. 1191996

103. van der Windt GJ, Everts B, Chang CH, Curtis JD, Freitas TC, Amiel E, et al. Mitochondrial respiratory capacity is a critical regulator of CD8+ $\mathrm{T}$ cell memory development. Immunity (2012) 36:68-78. doi:10.1016/j. immuni.2011.12.007

104. Song JJ, Ott HC. Organ engineering based on decellularized matrix scaffolds. Trends Mol Med (2011) 17:424-32. doi:10.1016/j. molmed.2011.03.005

105. Darby IA, Laverdet B, Bonte F, Desmouliere A. Fibroblasts and myofibroblasts in wound healing. Clin Cosmet Investig Dermatol (2014) 7:301-11. doi:10.2147/CCID.S50046

106. Witz IP. The tumor microenvironment: the making of a paradigm. Cancer Microenviron (2009) 2(Suppl 1):9-17. doi:10.1007/s12307-009-0025-8

107. Bhome R, Bullock MD, Al Saihati HA, Goh RW, Primrose JN, Sayan AE, et al. A top-down view of the tumor microenvironment: structure, cells and signaling. Front Cell Dev Biol (2015) 3:33. doi:10.3389/ fcell.2015.00033
108. Vannucci L. Stroma as an active player in the development of the tumor microenvironment. Cancer Microenviron (2015) 8:159-66. doi:10.1007/ s12307-014-0150-x

109. Lee D, Ham IH, Son SY, Han SU, Kim YB, Hur H. Intratumor stromal proportion predicts aggressive phenotype of gastric signet ring cell carcinomas. Gastric Cancer (2016) 1-11. doi:10.1007/s10120-016-0669-2

110. Martinez-Outschoorn UE, Lisanti MP, Sotgia F. Catabolic cancerassociated fibroblasts transfer energy and biomass to anabolic cancer cells, fueling tumor growth. Semin Cancer Biol (2014) 25:47-60. doi:10.1016/j. semcancer.2014.01.005

111. Fiaschi T, Marini A, Giannoni E, Taddei ML, Gandellini P, De Donatis A, et al. Reciprocal metabolic reprogramming through lactate shuttle coordinately influences tumor-stroma interplay. Cancer Res (2012) 72:5130-40. doi:10.1158/0008-5472.CAN-12-1949

112. Bonuccelli G, Avnet S, Grisendi G, Salerno M, Granchi D, Dominici M, et al. Role of mesenchymal stem cells in osteosarcoma and metabolic reprogramming of tumor cells. Oncotarget (2014) 5:7575-88. doi:10.18632/ oncotarget.2243

113. Whitaker-MenezesD,Martinez-OutschoornUE,LinZ,ErtelA,FlomenbergN, Witkiewicz AK, et al. Evidence for a stromal-epithelial "lactate shuttle" in human tumors: MCT4 is a marker of oxidative stress in cancer-associated fibroblasts. Cell Cycle (2011) 10:1772-83. doi:10.4161/cc.10.11.15659

114. Shi H, Jiang H, Wang L, Cao Y, Liu P, Xu X, et al. Overexpression of monocarboxylate anion transporter 1 and 4 in T24-induced cancer-associated fibroblasts regulates the progression of bladder cancer cells in a 3D microfluidic device. Cell Cycle (2015) 14:3058-65. doi:10.1080/15384101.2015. 1053666

115. Colegio OR. Lactic acid polarizes macrophages to a tumor-promoting state. Oncoimmunology (2016) 5:e1014774. doi:10.1080/2162402X.2015.1014774

116. Colegio OR, Chu NQ, Szabo AL, Chu T, Rhebergen AM, Jairam V, et al. Functional polarization of tumour-associated macrophages by tumourderived lactic acid. Nature (2014) 513:559-63. doi:10.1038/nature13490

117. Gordon S, Martinez FO. Alternative activation of macrophages: mechanism and functions. Immunity (2010) 32:593-604. doi:10.1016/j.immuni. 2010.05.007

118. Liu M, Quek LE, Sultani G, Turner N. Epithelial-mesenchymal transition induction is associated with augmented glucose uptake and lactate production in pancreatic ductal adenocarcinoma. Cancer Metab (2016) 4:19. doi:10.1186/s40170-016-0160-x

119. Verdegem D, Moens S, Stapor P, Carmeliet P. Endothelial cell metabolism: parallels and divergences with cancer cell metabolism. Cancer Metab (2014) 2:19. doi:10.1186/2049-3002-2-19

120. Romero IL, Mukherjee A, Kenny HA, Litchfield LM, Lengyel E. Molecular pathways: trafficking of metabolic resources in the tumor microenvironment. Clin Cancer Res (2015) 21:680-6. doi:10.1158/1078-0432.CCR-14-2198

121. Berg JM, Tymoczko JL, Stryer L. Section 30.2, each organ has a unique metabolic profile. In: Freeman WH, editor. Biochemistry, 5th edn. New York: WH Freeman and Company (2002). Available from: https://www.ncbi.nlm. nih.gov/books/NBK22436/

122. Hanahan D, Coussens LM. Accessories to the crime: functions of cells recruited to the tumor microenvironment. Cancer Cell (2012) 21:309-22. doi:10.1016/j.ccr.2012.02.022

123. Ho PC, Bihuniak JD, Macintyre AN, Staron M, Liu X, Amezquita R, et al. Phosphoenolpyruvate is a metabolic checkpoint of anti-tumor $\mathrm{T}$ cell responses. Cell (2015) 162:1217-28. doi:10.1016/j.cell.2015.08.012

124. Li H, Zhang J, Chen SW, Liu LL, Li L, Gao F, et al. Cancer-associated fibroblasts provide a suitable microenvironment for tumor development and progression in oral tongue squamous cancer. J Transl Med (2015) 13:198. doi:10.1186/s12967-015-0551-8

125. Izar B, Joyce CE, Goff S, Cho NL, Shah PM, Sharma G, et al. Bidirectional cross talk between patient-derived melanoma and cancer-associated fibroblasts promotes invasion and proliferation. Pigment Cell Melanoma Res (2016) 29:656-68. doi:10.1111/pcmr.12513

126. Olumi AF, Grossfeld GD, Hayward SW, Carroll PR, Tlsty TD, Cunha GR. Carcinoma-associated fibroblasts direct tumor progression of initiated human prostatic epithelium. Cancer Res (1999) 59:5002-11.

127. LaGory EL, Giaccia AJ. The ever-expanding role of HIF in tumour and stromal biology. Nat Cell Biol (2016) 18:356-65. doi:10.1038/ncb3330 
128. Imtiyaz HZ, Simon MC. Hypoxia-inducible factors as essential regulators of inflammation. Curr Top Microbiol Immunol (2010) 345:105-20. doi:10.1007/82_2010_74

129. Semenza GL. Targeting HIF-1 for cancer therapy. Nat Rev Cancer (2003) 3:721-32. doi:10.1038/nrc1187

130. Bertout JA, Patel SA, Simon MC. The impact of $\mathrm{O}_{2}$ availability on human cancer. Nat Rev Cancer (2008) 8:967-75. doi:10.1038/nrc2540

131. Clambey ET, McNamee EN, Westrich JA, Glover LE, Campbell EL, Jedlicka P, et al. Hypoxia-inducible factor-1 alpha-dependent induction of FoxP3 drives regulatory T-cell abundance and function during inflammatory hypoxia of the mucosa. Proc Natl Acad Sci U S A (2012) 109:E2784-93. doi:10.1073/ pnas. 1202366109

132. Dang EV, Barbi J, Yang HY, Jinasena D, Yu H, Zheng Y, et al. Control of $\mathrm{T}(\mathrm{H}) 17 / \mathrm{T}(\mathrm{reg})$ balance by hypoxia-inducible factor 1. Cell (2011) 146:772-84. doi:10.1016/j.cell.2011.07.033

133. Ben-Shoshan J, Maysel-Auslender S, Mor A, Keren G, George J. Hypoxia controls CD4+CD25+ regulatory T-cell homeostasis via hypoxiainducible factor-1alpha. Eur J Immunol (2008) 38:2412-8. doi:10.1002/ eji.200838318

134. Shi LZ, Wang R, Huang G, Vogel P, Neale G, Green DR, et al. HIFlalphadependent glycolytic pathway orchestrates a metabolic checkpoint for the differentiation of TH17 and Treg cells. J Exp Med (2011) 208:1367-76. doi:10.1084/jem.20110278

135. Laoui D, Van Overmeire E, Di Conza G, Aldeni C, Keirsse J, Morias Y, et al. Tumor hypoxia does not drive differentiation of tumor-associated macrophages but rather fine-tunes the M2-like macrophage population. Cancer Res (2014) 74:24-30. doi:10.1158/0008-5472.CAN-13-1196

136. Stockmann C, Doedens A, Weidemann A, Zhang N, Takeda N, Greenberg JI, et al. Deletion of vascular endothelial growth factor in myeloid cells accelerates tumorigenesis. Nature (2008) 456:814-8. doi:10.1038/nature07445

137. Wenes M, Shang M, Di Matteo M, Goveia J, Martin-Perez R, Serneels J, et al. Macrophage metabolism controls tumor blood vessel morphogenesis and metastasis. Cell Metab (2016) 24:701-15. doi:10.1016/j.cmet.2016.09.008

138. Galvan-Pena S, O’Neill LA. Metabolic reprograming in macrophage polarization. Front Immunol (2014) 5:420. doi:10.3389/fimmu.2014.00420

139. Jetten N, Verbruggen S, Gijbels MJ, Post MJ, De Winther MP, Donners MM. Anti-inflammatory M2, but not pro-inflammatory M1 macrophages promote angiogenesis in vivo. Angiogenesis (2014) 17:109-18. doi:10.1007/s10456-013-9381-6

140. Jones CV, Williams TM, Walker KA, Dickinson H, Sakkal S, Rumballe BA, et al. M2 macrophage polarisation is associated with alveolar formation during postnatal lung development. Respir Res (2013) 14:41. doi:10.1186/1465-9921-14-41

141. Balkwill FR, Capasso M, Hagemann T. The tumor microenvironment at a glance. J Cell Sci (2012) 125:5591-6. doi:10.1242/jcs.116392

142. Kang CW, Dutta A, Chang LY, Mahalingam J, Lin YC, Chiang JM, et al. Apoptosis of tumor infiltrating effector TIM-3+CD8+ T cells in colon cancer. Sci Rep (2015) 5:15659. doi:10.1038/srep15659

143. Enninga EA, Nevala WK, Holtan SG, Leontovich AA, Markovic SN. Galectin-9 modulates immunity by promoting Th2/M2 differentiation and impacts survival in patients with metastatic melanoma. Melanoma Res (2016) 26:429-41. doi:10.1097/CMR.0000000000000281

144. Wu S, Rhee KJ, Albesiano E, Rabizadeh S, Wu X, Yen HR, et al. A human colonic commensal promotes colon tumorigenesis via activation of T helper type $17 \mathrm{~T}$ cell responses. Nat Med (2009) 15:1016-22. doi:10.1038/ nm.2015

145. Sharp SP, Avram D, Stain SC, Lee EC. Local and systemic Th17 immune response associated with advanced stage colon cancer. J Surg Res (2017) 208:180-6. doi:10.1016/j.jss.2016.09.038

146. Han Y, Ye A, Bi L, Wu J, Yu K, Zhang S. Th17 cells and interleukin-17 increase with poor prognosis in patients with acute myeloid leukemia. Cancer Sci (2014) 105:933-42. doi:10.1111/cas.12459

147. Cramer T, Yamanishi Y, Clausen BE, Forster I, Pawlinski R, Mackman N, et al. HIF-1alpha is essential for myeloid cell-mediated inflammation. Cell (2003) 112:645-57. doi:10.1016/S0092-8674(03)00154-5

148. Corzo CA, Condamine T, Lu L, Cotter MJ, Youn JI, Cheng P, et al. HIF-1alpha regulates function and differentiation of myeloid-derived suppressor cells in the tumor microenvironment. J Exp Med (2010) 207:2439-53. doi:10.1084/ jem.20100587
149. Schroeder T, Yuan H, Viglianti BL, Peltz C, Asopa S, Vujaskovic Z, et al. Spatial heterogeneity and oxygen dependence of glucose consumption in R3230Ac and fibrosarcomas of the Fischer 344 rat. Cancer Res (2005) 65:5163-71. doi:10.1158/0008-5472.CAN-04-3900

150. MacIver NJ, Michalek RD, Rathmell JC. Metabolic regulation of T lymphocytes. Annu Rev Immunol (2013) 31:259-83. doi:10.1146/ annurev-immunol-032712-095956

151. Cham CM, Driessens G, O'Keefe JP, Gajewski TF. Glucose deprivation inhibits multiple key gene expression events and effector functions in CD8+ T cells. Eur J Immunol (2008) 38:2438-50. doi:10.1002/eji.200838289

152. Zheng Y, Delgoffe GM, Meyer CF, Chan W, Powell JD. Anergic T cells are metabolically anergic. JImmunol (2009) 183:6095-101. doi:10.4049/ jimmunol.0803510

153. Chang CH, Curtis JD, Maggi LB Jr, Faubert B, Villarino AV, O’Sullivan D, et al. Posttranscriptional control of T cell effector function by aerobic glycolysis. Cell (2013) 153:1239-51. doi:10.1016/j.cell.2013.05.016

154. Hanahan D, Weinberg RA. Hallmarks of cancer: the next generation. Cell (2011) 144:646-74. doi:10.1016/j.cell.2011.02.013

155. Plas DR, Thompson CB. Cell metabolism in the regulation of programmed cell death. Trends Endocrinol Metab (2002) 13:75-8. doi:10.1016/ S1043-2760(01)00528-8

156. Cory S, Adams JM. The Bcl2 family: regulators of the cellular life-or-death switch. Nat Rev Cancer (2002) 2:647-56. doi:10.1038/nrc883

157. Scharping NE, Menk AV, Moreci RS, Whetstone RD, Dadey RE, Watkins SC, et al. The tumor microenvironment represses $\mathrm{T}$ cell mitochondrial biogenesis to drive intratumoral T cell metabolic insufficiency and dysfunction. Immunity (2016) 45:374-88. doi:10.1016/j.immuni.2016.07.009

158. Yang M, Soga T, Pollard PJ. Oncometabolites: linking altered metabolism with cancer. J Clin Invest (2013) 123:3652-8. doi:10.1172/JCI67228

159. Fischer K, Hoffmann P, Voelkl S, Meidenbauer N, Ammer J, Edinger M, et al. Inhibitory effect of tumor cell-derived lactic acid on human T cells. Blood (2007) 109:3812-9. doi:10.1182/blood-2006-07-035972

160. Fukumura D, Xu L, Chen Y, Gohongi T, Seed B, Jain RK. Hypoxia and acidosis independently up-regulate vascular endothelial growth factor transcription in brain tumors in vivo. Cancer Res (2001) 61:6020-4.

161. Calcinotto A, Filipazzi P, Grioni M, Iero M, De Milito A, Ricupito A, et al. Modulation of microenvironment acidity reverses anergy in human and murine tumor-infiltrating T lymphocytes. Cancer Res (2012) 72:2746-56. doi:10.1158/0008-5472.CAN-11-1272

162. Ohashi T, Akazawa T, Aoki M, Kuze B, Mizuta K, Ito Y, et al. Dichloroacetate improves immune dysfunction caused by tumor-secreted lactic acid and increases antitumor immunoreactivity. Int J Cancer (2013) 133:1107-18. doi:10.1002/ijc. 28114

163. Sattler UG, Meyer SS, Quennet V, Hoerner C, Knoerzer H, Fabian C, et al. Glycolytic metabolism and tumour response to fractionated irradiation. Radiother Oncol (2010) 94:102-9. doi:10.1016/j.radonc.2009.11.007

164. Martinez D, Vermeulen M, Trevani A, Ceballos A, Sabatte J, Gamberale R, et al. Extracellular acidosis induces neutrophil activation by a mechanism dependent on activation of phosphatidylinositol 3-kinase/Akt and ERK pathways. J Immunol (2006) 176:1163-71. doi:10.4049/jimmunol. 176.2.1163

165. Fischer B, Muller B, Fischer KG, Baur N, Kreutz W. Acidic pH inhibits non-MHC-restricted killer cell functions. Clin Immunol (2000) 96:252-63. doi:10.1006/clim.2000.4904

166. Muller B, Fischer B, Kreutz W. An acidic microenvironment impairs the generation of non-major histocompatibility complex-restricted killer cells. Immunology (2000) 99:375-84. doi:10.1046/j.1365-2567.2000.00975.x

167. Tannahill GM, Curtis AM, Adamik J, Palsson-McDermott EM, McGettrick AF, Goel G, et al. Succinate is an inflammatory signal that induces IL-1beta through HIF-1alpha. Nature (2013) 496:238-42. doi:10.1038/nature11986

168. Rubic T, Lametschwandtner G, Jost S, Hinteregger S, Kund J, CarballidoPerrig N, et al. Triggering the succinate receptor GPR91 on dendritic cells enhances immunity. Nat Immunol (2008) 9:1261-9. doi:10.1038/ ni. 1657

169. Villalba M, Rathore MG, Lopez-Royuela N, Krzywinska E, Garaude J, Allende-Vega N. From tumor cell metabolism to tumor immune escape. Int J Biochem Cell Biol (2013) 45:106-13. doi:10.1016/j. biocel.2012.04.024 
170. Mocellin S, Bronte V, Nitti D. Nitric oxide, a double edged sword in cancer biology: searching for therapeutic opportunities. Med Res Rev (2007) 27:317-52. doi:10.1002/med.20092

171. Cederbaum SD, Yu H, Grody WW, Kern RM, Yoo P, Iyer RK. Arginases I and II: do their functions overlap? Mol Genet Metab (2004) 81(Suppl 1):S38-44. doi:10.1016/j.ymgme.2003.10.012

172. Brito C, Naviliat M, Tiscornia AC, Vuillier F, Gualco G, Dighiero G, et al. Peroxynitrite inhibits $\mathrm{T}$ lymphocyte activation and proliferation by promoting impairment of tyrosine phosphorylation and peroxynitrite-driven apoptotic death. J Immunol (1999) 162:3356-66.

173. Aulak KS, Miyagi M, Yan L, West KA, Massillon D, Crabb JW, et al. Proteomic method identifies proteins nitrated in vivo during inflammatory challenge. Proc Natl Acad Sci U S A (2001) 98:12056-61. doi:10.1073/pnas.221269198

174. Nagaraj S, Gupta K, Pisarev V, Kinarsky L, Sherman S, Kang L, et al. Altered recognition of antigen is a mechanism of CD8+ T cell tolerance in cancer. Nat Med (2007) 13:828-35. doi:10.1038/nm1609

175. Kasic T, Colombo P, Soldani C, Wang CM, Miranda E, Roncalli M, et al. Modulation of human T-cell functions by reactive nitrogen species. Eur J Immunol (2011) 41:1843-9. doi:10.1002/eji.201040868

176. Bronte V, Kasic T, Gri G, Gallana K, Borsellino G, Marigo I, et al. Boosting antitumor responses of $\mathrm{T}$ lymphocytes infiltrating human prostate cancers. J Exp Med (2005) 201:1257-68. doi:10.1084/jem.20042028

177. Predonzani A, Cali B, Agnellini AH, Molon B. Spotlights on immunological effects of reactive nitrogen species: when inflammation says nitric oxide. World J Exp Med (2015) 5:64-76. doi:10.5493/wjem.v5.i2.64

178. Rodriguez PC, Quiceno DG, Zabaleta J, Ortiz B, Zea AH, Piazuelo MB, et al. Arginase I production in the tumor microenvironment by mature myeloid cells inhibits T-cell receptor expression and antigen-specific T-cell responses. Cancer Res (2004) 64:5839-49. doi:10.1158/0008-5472.CAN-04-0465

179. Bronte V, Zanovello P. Regulation of immune responses by L-arginine metabolism. Nat Rev Immunol (2005) 5:641-54. doi:10.1038/nri1668

180. Dillon BJ, Prieto VG, Curley SA, Ensor CM, Holtsberg FW, Bomalaski JS, et al. Incidence and distribution of argininosuccinate synthetase deficiency in human cancers: a method for identifying cancers sensitive to arginine deprivation. Cancer (2004) 100:826-33. doi:10.1002/cncr.20057

181. Phillips MM, Sheaff MT, Szlosarek PW. Targeting arginine-dependent cancers with arginine-degrading enzymes: opportunities and challenges. Cancer Res Treat (2013) 45:251-62. doi:10.4143/crt.2013.45.4.251

182. Srivastava MK, Sinha P, Clements VK, Rodriguez P, Ostrand-Rosenberg S. Myeloid-derived suppressor cells inhibit T-cell activation by depleting cystine and cysteine. Cancer Res (2010) 70:68-77. doi:10.1158/0008-5472. CAN-09-2587

183. Munn DH, Mellor AL. Indoleamine 2,3 dioxygenase and metabolic control of immune responses. Trends Immunol (2013) 34:137-43. doi:10.1016/j. it.2012.10.001

184. Vacchelli E, Aranda F, Eggermont A, Sautes-Fridman C, Tartour E, Kennedy EP, et al. Trial watch: IDO inhibitors in cancer therapy. Oncoimmunology (2014) 3:e957994. doi:10.4161/21624011.2014.957994

185. Weinlich G, Murr C, Richardsen L, Winkler C, Fuchs D. Decreased serum tryptophan concentration predicts poor prognosis in malignant melanoma patients. Dermatology (2007) 214:8-14. doi:10.1159/000096906

186. Godin-Ethier J, Hanafi LA, Piccirillo CA, Lapointe R. Indoleamine 2,3-dioxygenase expression in human cancers: clinical and immunologic perspectives. Clin Cancer Res (2011) 17:6985-91. doi:10.1158/1078-0432.CCR-11-1331

187. Gottfried E, Kreutz M, Mackensen A. Tumor metabolism as modulator of immune response and tumor progression. Semin Cancer Biol (2012) 22:335-41. doi:10.1016/j.semcancer.2012.02.009

188. Mellor AL, Chandler P, Baban B, Hansen AM, Marshall B, Pihkala J, et al. Specific subsets of murine dendritic cells acquire potent $\mathrm{T}$ cell regulatory functions following CTLA4-mediated induction of indoleamine 2,3 dioxygenase. Int Immunol (2004) 16:1391-401. doi:10.1093/intimm/dxh140

189. Maciolek JA, Pasternak JA, Wilson HL. Metabolism of activated T lymphocytes. Curr Opin Immunol (2014) 27:60-74. doi:10.1016/j.coi.2014.01.006

190. Rabinowitz JD, White E. Autophagy and metabolism. Science (2010) 330:1344-8. doi:10.1126/science.1193497

191. Egan DF, Shackelford DB, Mihaylova MM, Gelino S, Kohnz RA, Mair W, et al. Phosphorylation of ULK1 (hATG1) by AMP-activated protein kinase connects energy sensing to mitophagy. Science (2011) 331:456-61. doi:10.1126/ science. 1196371
192. Mason EF, Rathmell JC. Cell metabolism: an essential link between cell growth and apoptosis. Biochim Biophys Acta (2011) 1813:645-54. doi:10.1016/j. bbamcr.2010.08.011

193. Shackelford DB, Shaw RJ. The LKB1-AMPK pathway: metabolism and growth control in tumour suppression. Nat Rev Cancer (2009) 9:563-75. doi: $10.1038 / \mathrm{nrc} 2676$

194. Son HJ, Lee J, Lee SY, Kim EK, Park MJ, Kim KW, et al. Metformin attenuates experimental autoimmune arthritis through reciprocal regulation of Th17/ Treg balance and osteoclastogenesis. Mediators Inflamm (2014) 2014:973986. doi:10.1155/2014/973986

195. Murray IA, Patterson AD, Perdew GH. Aryl hydrocarbon receptor ligands in cancer: friend and foe. Nat Rev Cancer (2014) 14:801-14. doi:10.1038/ nrc3846

196. Chen W, Jin W, Hardegen N, Lei KJ, Li L, Marinos N, et al. Conversion of peripheral CD4+CD25- naive $\mathrm{T}$ cells to $\mathrm{CD} 4+\mathrm{CD} 25+$ regulatory $\mathrm{T}$ cells by TGF-beta induction of transcription factor Foxp3. J Exp Med (2003) 198:1875-86. doi:10.1084/jem.20030152

197. Curiel TJ, Coukos G, Zou L, Alvarez X, Cheng P, Mottram P, et al. Specific recruitment of regulatory $\mathrm{T}$ cells in ovarian carcinoma fosters immune privilege and predicts reduced survival. Nat Med (2004) 10:942-9. doi:10.1038/ nm1093

198. Wilke CM, Wu K, Zhao E, Wang G, Zou W. Prognostic significance of regulatory T cells in tumor. Int J Cancer (2010) 127:748-58. doi:10.1002/ijc.25464

199. Gerriets VA, Kishton RJ, Johnson MO, Cohen S, Siska PJ, Nichols AG, et al. Foxp3 and toll-like receptor signaling balance Treg cell anabolic metabolism for suppression. Nat Immunol (2016) 17:1459-66. doi:10.1038/ni.3577

200. Macintyre AN, Gerriets VA, Nichols AG, Michalek RD, Rudolph MC, Deoliveira D, et al. The glucose transporter Glut1 is selectively essential for CD4 T cell activation and effector function. Cell Metab (2014) 20:61-72. doi:10.1016/j.cmet.2014.05.004

201. Sinclair LV, Rolf J, Emslie E, Shi YB, Taylor PM, Cantrell DA. Control of amino-acid transport by antigen receptors coordinates the metabolic reprogramming essential for T cell differentiation. Nat Immunol (2013) 14:500-8. doi:10.1038/ni.2556

202. Wieman HL, Wofford JA, Rathmell JC. Cytokine stimulation promotes glucose uptake via phosphatidylinositol-3 kinase/Akt regulation of Glut1 activity and trafficking. Mol Biol Cell (2007) 18:1437-46. doi:10.1091/mbc. E06-07-0593

203. McCracken AN, Edinger AL. Nutrient transporters: the Achilles' heel of anabolism. Trends Endocrinol Metab (2013) 24:200-8. doi:10.1016/j. tem.2013.01.002

204. Parry RV, Chemnitz JM, Frauwirth KA, Lanfranco AR, Braunstein I, Kobayashi SV, et al. CTLA-4 and PD-1 receptors inhibit T-cell activation by distinct mechanisms. Mol Cell Biol (2005) 25:9543-53. doi:10.1128/ MCB.25.21.9543-9553.2005

205. Frauwirth KA, Riley JL, Harris MH, Parry RV, Rathmell JC, Plas DR, et al. The CD28 signaling pathway regulates glucose metabolism. Immunity (2002) 16:769-77. doi:10.1016/S1074-7613(02)00323-0

206. Doering TA, Crawford A, Angelosanto JM, Paley MA, Ziegler CG, Wherry EJ. Network analysis reveals centrally connected genes and pathways involved in CD8+ T cell exhaustion versus memory. Immunity (2012) 37:1130-44. doi:10.1016/j.immuni.2012.08.021

207. Shimatani K, Nakashima Y, Hattori M, Hamazaki Y, Minato N. PD-1+ memory phenotype CD4+ T cells expressing C/EBPalpha underlie $\mathrm{T}$ cell immunodepression in senescence and leukemia. Proc Natl Acad Sci U S A (2009) 106:15807-12. doi:10.1073/pnas.0908805106

208. Patsoukis N, Li L, Sari D, Petkova V, Boussiotis VA. PD-1 increases PTEN phosphatase activity while decreasing PTEN protein stability by inhibiting casein kinase 2. Mol Cell Biol (2013) 33:3091-8. doi:10.1128/MCB. 00319-13

209. Saha A,AoyamaK, TaylorPA,KoehnBH,VeenstraRG,Panoskaltsis-MortariA, et al. Host programmed death ligand 1 is dominant over programmed death ligand 2 expression in regulating graft-versus-host disease lethality. Blood (2013) 122:3062-73. doi:10.1182/blood-2013-05-500801

210. Walker LS, Sansom DM. Confusing signals: recent progress in CTLA-4 biology. Trends Immunol (2015) 36:63-70. doi:10.1016/j.it.2014.12.001

211. Chen X, Fosco D, Kline DE, Meng L, Nishi S, Savage PA, et al. PD-1 regulates extrathymic regulatory T-cell differentiation. Eur J Immunol (2014) 44:2603-16. doi:10.1002/eji.201344423 
212. Ha TY. The role of regulatory T cells in cancer. Immune Netw (2009) 9:209-35. doi:10.4110/in.2009.9.6.209

213. Whiteside TL. What are regulatory $\mathrm{T}$ cells (Treg) regulating in cancer and why? Semin Cancer Biol (2012) 22:327-34. doi:10.1016/j.semcancer.2012. 03.004

214. Patsoukis N, Bardhan K, Chatterjee P, Sari D, Liu B, Bell LN, et al. PD-1 alters T-cell metabolic reprogramming by inhibiting glycolysis and promoting lipolysis and fatty acid oxidation. Nat Commun (2015) 6:6692. doi:10.1038/ ncomms 7692

215. Barsoum IB, Koti M, Siemens DR, Graham CH. Mechanisms of hypoxiamediated immune escape in cancer. Cancer Res (2014) 74:7185-90. doi:10.1158/0008-5472.CAN-14-2598

216. Arreygue-Garcia NA, Daneri-Navarro A, del Toro-Arreola A, Cid-Arregui A, Gonzalez-Ramella O, Jave-Suarez LF, et al. Augmented serum level of major histocompatibility complex class I-related chain A (MICA) protein and reduced NKG2D expression on $\mathrm{NK}$ and $\mathrm{T}$ cells in patients with cervical cancer and precursor lesions. BMC Cancer (2008) 8:16. doi:10.1186/1471-2407-8-16

217. Barsoum IB, Hamilton TK, Li X, Cotechini T, Miles EA, Siemens DR, et al. Hypoxia induces escape from innate immunity in cancer cells via increased expression of ADAM10: role of nitric oxide. Cancer Res (2011) 71:7433-41. doi:10.1158/0008-5472.CAN-11-2104

218. Ahmadzadeh M, Johnson LA, Heemskerk B, Wunderlich JR, Dudley ME, White DE, et al. Tumor antigen-specific CD8 T cells infiltrating the tumor express high levels of PD-1 and are functionally impaired. Blood (2009) 114:1537-44. doi:10.1182/blood-2008-12-195792

219. Page DB, Postow MA, Callahan MK, Allison JP, Wolchok JD. Immune modulation in cancer with antibodies. Annu Rev Med (2014) 65:185-202. doi:10.1146/annurev-med-092012-112807

220. Chen TC, Wu CT, Wang CP, Hsu WL, Yang TL, Lou PJ, et al. Associations among pretreatment tumor necrosis and the expression of HIF-1alpha and PD-L1 in advanced oral squamous cell carcinoma and the prognostic impact thereof. Oral Oncol (2015) 51:1004-10. doi:10.1016/j.oraloncology.2015.08.011

221. Barsoum IB, Smallwood CA, Siemens DR, Graham CH. A mechanism of hypoxia-mediated escape from adaptive immunity in cancer cells. Cancer Res (2014) 74:665-74. doi:10.1158/0008-5472.CAN-14-2598

222. Guido C, Whitaker-Menezes D, Capparelli C, Balliet R, Lin Z, Pestell RG, et al. Metabolic reprogramming of cancer-associated fibroblasts by TGF-beta drives tumor growth: connecting TGF-beta signaling with "Warburg-like" cancer metabolism and L-lactate production. Cell Cycle (2012) 11:3019-35. doi:10.4161/cc.21384

223. Guido C, Whitaker-Menezes D, Lin Z, Pestell RG, Howell A, Zimmers TA, et al. Mitochondrial fission induces glycolytic reprogramming in cancer-associated myofibroblasts, driving stromal lactate production, and early tumor growth. Oncotarget (2012) 3:798-810. doi:10.18632/oncotarget.574

224. Cai M, He J, Xiong J, Tay LW, Wang Z, Rog C, et al. Phospholipase D1-regulated autophagy supplies free fatty acids to counter nutrient stress in cancer cells. Cell Death Dis (2016) 7:e2448. doi:10.1038/cddis.2016.355

225. Schafer M, Werner S. Cancer as an overhealing wound: an old hypothesis revisited. Nat Rev Mol Cell Biol (2008) 9:628-38. doi:10.1038/nrm2455

226. Pavlides S, Whitaker-Menezes D, Castello-Cros R, Flomenberg N, Witkiewicz AK, Frank PG, et al. The reverse Warburg effect: aerobic glycolysis in cancer associated fibroblasts and the tumor stroma. Cell Cycle (2009) 8:3984-4001. doi: $10.4161 /$ cc.8.23.10238

227. Martinez-Outschoorn UE, Balliet R, Lin Z, Whitaker-Menezes D, Birbe RC, Bombonati A, et al. BRCA1 mutations drive oxidative stress and glycolysis in the tumor microenvironment: implications for breast cancer prevention with antioxidant therapies. Cell Cycle (2012) 11:4402-13. doi:10.4161/cc.22776

228. Xu XD, Shao SX, Cao YW, Yang XC, Shi HQ, Wang YL, et al. The study of energy metabolism in bladder cancer cells in co-culture conditions using a microfluidic chip. Int J Clin Exp Med (2015) 8:12327-36.

229. Yu T, Yang G, Hou Y, Tang X, Wu C, Wu XA, et al. Cytoplasmic GPER translocation in cancer-associated fibroblasts mediates cAMP/PKA/CREB/ glycolytic axis to confer tumor cells with multidrug resistance. Oncogene (2016) 1-15. doi:10.1038/onc.2016.370

230. Arcucci A, Ruocco MR, Granato G, Sacco AM, Montagnani S. Cancer: an oxidative crosstalk between solid tumor cells and cancer associated fibroblasts. Biomed Res Int (2016) 2016:4502846. doi:10.1155/2016/4502846

231. Pertega-Gomes N, Vizcaino JR, Attig J, Jurmeister S, Lopes C, Baltazar F. A lactate shuttle system between tumour and stromal cells is associated with poor prognosis in prostate cancer. BMC Cancer (2014) 14:352. doi:10.1186/1471-2407-14-352

232. Kim Y, Choi JW, Lee JH, Kim YS. Expression of lactate/H(+) symporters MCT1 and MCT4 and their chaperone CD147 predicts tumor progression in clear cell renal cell carcinoma: immunohistochemical and the Cancer Genome Atlas data analyses. Hum Pathol (2015) 46:104-12. doi:10.1016/j. humpath.2014.09.013

233. Miranda-Goncalves V, Granja S, Martinho O, Honavar M, Pojo M, Costa BM, et al. Hypoxia-mediated upregulation of MCT1 expression supports the glycolytic phenotype of glioblastomas. Oncotarget (2016) 7:46335-53. doi:10.18632/oncotarget.10114

234. Knudsen ES, Balaji U, Freinkman E, McCue P, Witkiewicz AK. Unique metabolic features of pancreatic cancer stroma: relevance to the tumor compartment, prognosis, and invasive potential. Oncotarget (2016) 7(48):78396-411. doi:10.18632/oncotarget.11893

235. Burbridge MF, West DC, Atassi G, Tucker GC. The effect of extracellular $\mathrm{pH}$ on angiogenesis in vitro. Angiogenesis (1999) 3:281-8. doi:10.1023/ A:1009092511894

236. Dong L, Li Z, Leffler NR, Asch AS, Chi JT, Yang LV. Acidosis activation of the proton-sensing GPR4 receptor stimulates vascular endothelial cell inflammatory responses revealed by transcriptome analysis. PLoS One (2013) 8:e61991. doi:10.1371/journal.pone.0061991

237. Zhang D, Wang Y, Shi Z, Liu J, Sun P, Hou X, et al. Metabolic reprogramming of cancer-associated fibroblasts by IDH3alpha downregulation. Cell Rep (2015) 10:1335-48. doi:10.1016/j.celrep.2015.02.006

238. Ko YH, Domingo-Vidal M, Roche M, Lin Z, Whitaker-Menezes D, Seifert E, et al. TP53-inducible glycolysis and apoptosis regulator (TIGAR) metabolically reprograms carcinoma and stromal cells in breast cancer. J Biol Chem (2016) 291:26291-303. doi:10.1074/jbc.M116.740209

239. Shim H, Dolde C, Lewis BC, Wu CS, Dang G, Jungmann RA, et al. c-Myc transactivation of LDH-A: implications for tumor metabolism and growth. Proc Natl Acad Sci U S A (1997) 94:6658-63. doi:10.1073/pnas.94.13.6658

240. Matoba S, Kang JG, Patino WD, Wragg A, Boehm M, Gavrilova O, et al. p53 regulates mitochondrial respiration. Science (2006) 312:1650-3. doi:10.1126/ science. 1126863

241. Won KY, Lim SJ, Kim GY, Kim YW, Han SA, Song JY, et al. Regulatory role of p53 in cancer metabolism via SCO2 and TIGAR in human breast cancer. Hum Pathol (2012) 43:221-8. doi:10.1016/j.humpath.2011.04.021

242. Choi J, Stradmann-Bellinghausen B, Yakubov E, Savaskan NE, RegnierVigouroux A. Glioblastoma cells induce differential glutamatergic gene expressions in human tumor-associated microglia/macrophages and monocyte-derived macrophages. Cancer Biol Ther (2015) 16:1205-13. doi:10.1080/ 15384047.2015.1056406

243. Seo JW, Choi J, Lee SY, Sung S, Yoo HJ, Kang MJ, et al. Autophagy is required for PDAC glutamine metabolism. Sci Rep (2016) 6:37594. doi:10.1038/ srep37594

244. Abramczyk H, Surmacki J, Kopec M, Olejnik AK, Lubecka-Pietruszewska K, Fabianowska-Majewska K. The role of lipid droplets and adipocytes in cancer. Raman imaging of cell cultures: MCF10A, MCF7, and MDA-MB-231 compared to adipocytes in cancerous human breast tissue. Analyst (2015) 140:2224-35. doi:10.1039/c4an01875c

245. Nieman KM, Kenny HA, Penicka CV, Ladanyi A, Buell-Gutbrod R, Zillhardt MR, et al. Adipocytes promote ovarian cancer metastasis and provide energy for rapid tumor growth. Nat Med (2011) 17:1498-503. doi: $10.1038 / \mathrm{nm} .2492$

246. Carter JC, Church FC. Mature breast adipocytes promote breast cancer cell motility. Exp Mol Pathol (2012) 92:312-7. doi:10.1016/j.yexmp.2012.03.005

247. D'Esposito V, Passaretti F, Hammarstedt A, Liguoro D, Terracciano D, Molea G, et al. Adipocyte-released insulin-like growth factor-1 is regulated by glucose and fatty acids and controls breast cancer cell growth in vitro. Diabetologia (2012) 55:2811-22. doi:10.1007/s00125-012-2629-7

248. Balaban S, Shearer RF, Lee LS, van Geldermalsen M, Schreuder M, Shtein HC, et al. Adipocyte lipolysis links obesity to breast cancer growth: adipocyte-derived fatty acids drive breast cancer cell proliferation and migration. Cancer Metab (2017) 5:1. doi:10.1186/s40170-016-0163-7

249. Wen YA, Xing X, Harris JW, Zaytseva YY, Mitov MI, Napier DL, et al. Adipocytes activate mitochondrial fatty acid oxidation and autophagy to promote tumor growth in colon cancer. Cell Death Dis (2017) 8:e2593. doi:10.1038/cddis.2017.21 
250. Guaita-Esteruelas S, Guma J, Masana L, Borras J. The peritumoural adipose tissue microenvironment and cancer. The roles of fatty acid binding protein 4 and fatty acid binding protein 5. Mol Cell Endocrinol (2017). doi:10.1016/j. mce.2017.02.002

251. Gazi E, Gardner P, Lockyer NP, Hart CA, Brown MD, Clarke NW. Direct evidence of lipid translocation between adipocytes and prostate cancer cells with imaging FTIR microspectroscopy. J Lipid Res (2007) 48:1846-56. doi:10.1194/jlr.M700131-JLR200

252. Pascual G, Avgustinova A, Mejetta S, Martin M, Castellanos A, Attolini CS, et al. Targeting metastasis-initiating cells through the fatty acid receptor CD36. Nature (2017) 541:41-5. doi:10.1038/nature20791

253. Li Z, Kang Y. Lipid metabolism fuels cancer's spread. Cell Metab (2017) 25:228-30. doi:10.1016/j.cmet.2017.01.016

254. Vander Heiden MG, Cantley LC, Thompson CB. Understanding the Warburg effect: the metabolic requirements of cell proliferation. Science (2009) 324:1029-33. doi:10.1126/science.1160809

255. Liu Y, Zuckier LS, Ghesani NV. Dominant uptake of fatty acid over glucose by prostate cells: a potential new diagnostic and therapeutic approach. Anticancer Res (2010) 30:369-74.

256. Deep G, Schlaepfer IR. Aberrant lipid metabolism promotes prostate cancer: role in cell survival under hypoxia and extracellular vesicles biogenesis. Int J Mol Sci (2016) 17:1061-74. doi:10.3390/ijms17071061

257. Staron MM, Gray SM, Marshall HD, Parish IA, Chen JH, Perry CJ, et al. The transcription factor FoxO1 sustains expression of the inhibitory receptor PD-1 and survival of antiviral CD8(+) T cells during chronic infection. Immunity (2014) 41:802-14. doi:10.1016/j.immuni.2014.10.013

258. Farooque A, Singh N, Adhikari JS, Afrin F, Dwarakanath BS. Enhanced antitumor immunity contributes to the radio-sensitization of Ehrlich ascites tumor by the glycolytic inhibitor 2-deoxy-D-glucose in mice. PLoS One (2014) 9:e108131. doi:10.1371/journal.pone.0108131

259. Farooque A, Afrin F, Adhikari JS, Dwarakanath BS. Polarization of macrophages towards M1 phenotype by a combination of 2-deoxy-d-glucose and radiation: implications for tumor therapy. Immunobiology (2016) 221:269-81. doi:10.1016/j.imbio.2015.10.009

260. Hubert S, Rissiek B, Klages K, Huehn J, Sparwasser T, Haag F, et al. Extracellular NAD+ shapes the Foxp3+ regulatory T cell compartment through the ART2P2X7 pathway. J Exp Med (2010) 207:2561-8. doi:10.1084/jem.20091154

261. Leone RD, Lo YC, Powell JD. A2aR antagonists: next generation checkpoint blockade for cancer immunotherapy. Comput Struct Biotechnol J (2015) 13:265-72. doi:10.1016/j.csbj.2015.03.008

262. Sonveaux P, Vegran F, Schroeder T, Wergin MC, Verrax J, Rabbani ZN, et al. Targeting lactate-fueled respiration selectively kills hypoxic tumor cells in mice. J Clin Invest (2008) 118:3930-42. doi:10.1172/JCI36843

263. Blagosklonny MV. Flavopiridol, an inhibitor of transcription: implications, problems and solutions. Cell Cycle (2004) 3:1537-42. doi:10.4161/cc.3. 12.1278

264. Lee K, Zhang H, Qian DZ, Rey S, Liu JO, Semenza GL. Acriflavine inhibits HIF-1 dimerization, tumor growth, and vascularization. Proc Natl Acad Sci U S A (2009) 106:17910-5. doi:10.1073/pnas.0909353106

265. Zhang H, Qian DZ, Tan YS, Lee K, Gao P, Ren YR, et al. Digoxin and other cardiac glycosides inhibit HIF-1alpha synthesis and block tumor growth. Proc Natl Acad Sci U S A (2008) 105:19579-86. doi:10.1073/pnas.0809763105

266. Yang QC, Zeng BF, Shi ZM, Dong Y, Jiang ZM, Huang J, et al. Inhibition of hypoxia-induced angiogenesis by trichostatin A via suppression of HIF-1a activity in human osteosarcoma. J Exp Clin Cancer Res (2006) 25:593-9.

267. Doedens AL, Phan AT, Stradner MH, Fujimoto JK, Nguyen JV, Yang E, et al. Hypoxia-inducible factors enhance the effector responses of CD8(+) T cells to persistent antigen. Nat Immunol (2013) 14:1173-82. doi:10.1038/ ni. 2714

268. Carmeliet P, Jain RK. Principles and mechanisms of vessel normalization for cancer and other angiogenic diseases. Nat Rev Drug Discov (2011) 10:417-27. doi: $10.1038 / \mathrm{nrd} 3455$

269. Maione F, Capano S, Regano D, Zentilin L, Giacca M, Casanovas O, et al. Semaphorin 3A overcomes cancer hypoxia and metastatic dissemination induced by antiangiogenic treatment in mice. J Clin Invest (2012) 122:183248. doi:10.1172/JCI58976

270. Sukumar M, Liu J, Ji Y, Subramanian M, Crompton JG, Yu Z, et al. Inhibiting glycolytic metabolism enhances CD8+ T cell memory and antitumor function. J Clin Invest (2013) 123:4479-88. doi:10.1172/JCI69589
271. Pearce EL, Walsh MC, Cejas PJ, Harms GM, Shen H, Wang LS, et al. Enhancing CD8 T-cell memory by modulating fatty acid metabolism. Nature (2009) 460:103-7. doi:10.1038/nature08097

272. Ben Sahra I, Regazzetti C, Robert G, Laurent K, Le Marchand-Brustel Y, Auberger P, et al. Metformin, independent of AMPK, induces mTOR inhibition and cell-cycle arrest through REDD1. Cancer Res (2011) 71:4366-72. doi:10.1158/0008-5472.CAN-10-1769

273. Blandino G, Valerio M, Cioce M, Mori F, Casadei L, Pulito C, et al. Metformin elicits anticancer effects through the sequential modulation of DICER and c-MYC. Nat Commun (2012) 3:865. doi:10.1038/ncomms1859

274. Waickman AT, Powell JD. mTOR, metabolism, and the regulation of T-cell differentiation and function. Immunol Rev (2012) 249:43-58. doi:10.1111/j.1600-065X.2012.01152.x

275. Rao RR, Li Q, Odunsi K, Shrikant PA. The mTOR kinase determines effector versus memory $\mathrm{CD} 8+\mathrm{T}$ cell fate by regulating the expression of transcription factors T-bet and Eomesodermin. Immunity (2010) 32:67-78. doi:10.1016/j. immuni.2009.10.010

276. Li C, Capan E, Zhao Y, Zhao J, Stolz D, Watkins SC, et al. Autophagy is induced in CD4+ T cells and important for the growth factor-withdrawal cell death. J Immunol (2006) 177:5163-8. doi:10.4049/jimmunol.177.8.5163

277. Law BK. Rapamycin: an anti-cancer immunosuppressant? Crit Rev Oncol Hematol (2005) 56:47-60. doi:10.1016/j.critrevonc.2004.09.009

278. Sharma MD, Shinde R, McGaha TL, Huang L, Holmgaard RB, Wolchok JD, et al. The PTEN pathway in Tregs is a critical driver of the suppressive tumor microenvironment. Sci Adv (2015) 1:e1500845. doi:10.1126/sciadv.1500845

279. Yang S, de Souza P, Alemao E, Purvis J. Quality of life in patients with advanced renal cell carcinoma treated with temsirolimus or interferon-alpha. Br J Cancer (2010) 102:1456-60. doi:10.1038/sj.bjc.6605647

280. Motzer RJ, Escudier B, Oudard S, Hutson TE, Porta C, Bracarda S, et al. Efficacy of everolimus in advanced renal cell carcinoma: a double-blind, randomised, placebo-controlled phase III trial. Lancet (2008) 372:449-56. doi:10.1016/S0140-6736(08)61039-9

281. Martelli AM, Chiarini F, Evangelisti C, Cappellini A, Buontempo F, Bressanin D, et al. Two hits are better than one: targeting both phosphatidylinositol 3-kinase and mammalian target of rapamycin as a therapeutic strategy for acute leukemia treatment. Oncotarget (2012) 3:371-94. doi:10.18632/ oncotarget.477

282. Wang H, Wang L, Zhang Y, Wang J, Deng Y, Lin D. Inhibition of glycolytic enzyme hexokinase II (HK2) suppresses lung tumor growth. Cancer Cell Int (2016) 16:9. doi:10.1186/s12935-016-0280-y

283. Botzer LE, Maman S, Sagi-Assif O, Meshel T, Nevo I, Yron I, et al. Hexokinase 2 is a determinant of neuroblastoma metastasis. Br J Cancer (2016) 114:759-66. doi: $10.1038 /$ bjc. 2016.26

284. Brown J. Effects of 2-deoxyglucose on carbohydrate metablism: review of the literature and studies in the rat. Metabolism (1962) 11:1098-112.

285. McComb RB, Yushok WD. Metabolism of ascites tumor cells. Iv. Enzymatic reactions involved in adenosinetriphosphate degradation induced by 2 -deoxyglucose. Cancer Res (1964) 24:198-205.

286. Dwarakanath BS. Cytotoxicity, radiosensitization, and chemosensitization of tumor cells by 2-deoxy-D-glucose in vitro. J Cancer Res Ther (2009) 5(Suppl 1):S27-31. doi:10.4103/0973-1482.55137

287. Mohanti BK, Rath GK, Anantha N, Kannan V, Das BS, Chandramouli BA, et al. Improving cancer radiotherapy with 2-deoxy-D-glucose: phase I/II clinical trials on human cerebral gliomas. Int J Radiat Oncol Biol Phys (1996) 35:103-11. doi:10.1016/S0360-3016(96)85017-6

288. Singh D, Banerji AK, Dwarakanath BS, Tripathi RP, Gupta JP, Mathew TL, et al. Optimizing cancer radiotherapy with 2-deoxy-d-glucose dose escalation studies in patients with glioblastoma multiforme. Strahlenther Onkol (2005) 181:507-14. doi:10.1007/s00066-005-1320-z

289. Dwarakanath BS, Singh D, Banerji AK, Sarin R, Venkataramana NK, Jalali R, et al. Clinical studies for improving radiotherapy with 2-deoxy-D-glucose: present status and future prospects. JCancer Res Ther (2009) 5(Suppl 1):S21-6. doi:10.4103/0973-1482.55136

290. Venkataramanaa NK, Venkatesh PK, Dwarakanath BS, Vani S. Protective effect on normal brain tissue during a combinational therapy of 2-deoxyd-glucose and hypofractionated irradiation in malignant gliomas. Asian J Neurosurg (2013) 8:9-14. doi:10.4103/1793-5482.110274

291. Marko AJ, Miller RA, Kelman A, Frauwirth KA. Induction of glucose metabolism in stimulated $\mathrm{T}$ lymphocytes is regulated by mitogen-activated 
protein kinase signaling. PLoS One (2010) 5:e15425. doi:10.1371/journal. pone. 0015425

292. Strum SB, Adalsteinsson O, Black RR, Segal D, Peress NL, Waldenfels J. Case report: sodium dichloroacetate (DCA) inhibition of the "Warburg Effect" in a human cancer patient: complete response in non-Hodgkin's lymphoma after disease progression with rituximab-CHOP. J Bioenerg Biomembr (2013) 45:307-15. doi:10.1007/s10863-013-9516-x

293. Jiang P, Du W, Wu M. Regulation of the pentose phosphate pathway in cancer. Protein Cell (2014) 5:592-602. doi:10.1007/s13238-014-0082-8

294. Tsouko E, Khan AS, White MA, Han JJ, Shi Y, Merchant FA, et al. Regulation of the pentose phosphate pathway by an androgen receptor-mTOR-mediated mechanism and its role in prostate cancer cell growth. Oncogenesis (2014) 3:e103. doi:10.1038/oncsis.2014.18

295. Sharma PK, Dwarakanath BS, Varshney R. Radiosensitization by 2-deoxyD-glucose and 6-aminonicotinamide involves activation of redox sensitive ASK1-JNK/p38MAPK signaling in head and neck cancer cells. Free Radic Biol Med (2012) 53:1500-13. doi:10.1016/j.freeradbiomed.2012.07.001

296. Varshney R, Dwarakanath B, Jain V. Radiosensitization by 6-aminonicotinamide and 2-deoxy-D-glucose in human cancer cells. Int J Radiat Biol (2005) 81:397-408. doi:10.1080/09553000500148590

297. Varshney R, Gupta S, Dwarakanath BS. Radiosensitization of murine Ehrlich ascites tumor by a combination of 2-deoxy-D-glucose and 6-aminonicotinamide. Technol Cancer Res Treat (2004) 3:659-63. doi:10. $1177 / 153303460400300616$

298. Zhu W, Ye L, Zhang J, Yu P, Wang H, Ye Z, et al. PFK15, a small molecule inhibitor of PFKFB3, induces cell cycle arrest, apoptosis and inhibits invasion in gastric cancer. PLoS One (2016) 11:e0163768. doi:10.1371/journal. pone. 0163768

299. Li S, Wu L, Feng J, Li J, Liu T, Zhang R, et al. In vitro and in vivo study of epigallocatechin-3-gallate-induced apoptosis in aerobic glycolytic hepatocellular carcinoma cells involving inhibition of phosphofructokinase activity. Sci Rep (2016) 6:28479. doi:10.1038/srep28479

300. Lian N, Jin H, Zhang F, Wu L, Shao J, Lu Y, et al. Curcumin inhibits aerobic glycolysis in hepatic stellate cells associated with activation of adenosine monophosphate-activated protein kinase. IUBMB Life (2016) 68:589-96. doi:10.1002/iub.1518

301. Cantelmo AR, Conradi LC, Brajic A, Goveia J, Kalucka J, Pircher A, et al. Inhibition of the glycolytic activator PFKFB3 in endothelium induces tumor vessel normalization, impairs metastasis, and improves chemotherapy. Cancer Cell (2016) 30:968-85. doi:10.1016/j.ccell.2016.10.006

302. Majkowska-Skrobek G, Augustyniak D, Lis P, Bartkowiak A, Gonchar M, Ko YH, et al. Killing multiple myeloma cells with the small molecule 3bromopyruvate: implications for therapy. Anticancer Drugs (2014) 25:673-82. doi:10.1097/CAD.0000000000000094

303. Lis P, Dylag M, Niedzwiecka K, Ko YH, Pedersen PL, Goffeau A, et al. The HK2 dependent "Warburg effect" and mitochondrial oxidative phosphorylation in cancer: targets for effective therapy with 3-bromopyruvate. Molecules (2016) 21:E1730. doi:10.3390/molecules21121730

304. Doherty JR, Cleveland JL. Targeting lactate metabolism for cancer therapeutics. J Clin Invest (2013) 123:3685-92. doi:10.1172/JCI69741

305. Papaldo P, Lopez M, Cortesi E, Cammilluzzi E, Antimi M, Terzoli E, et al. Addition of either lonidamine or granulocyte colony-stimulating factor does not improve survival in early breast cancer patients treated with highdose epirubicin and cyclophosphamide. JClin Oncol (2003) 21:3462-8. doi:10.1200/JCO.2003.03.034

306. Di Cosimo S, Ferretti G, Papaldo P, Carlini P, Fabi A, Cognetti F. Lonidamine: efficacy and safety in clinical trials for the treatment of solid tumors. Drugs Today (Barc) (2003) 39:157-74. doi:10.1358/dot.2003.39.3.799451

307. Fang J, Quinones QJ, Holman TL, Morowitz MJ, Wang Q, Zhao H, et al. The H+-linked monocarboxylate transporter (MCT1/SLC16A1): a potential therapeutic target for high-risk neuroblastoma. Mol Pharmacol (2006) 70:2108-15. doi:10.1124/mol.106.026245

308. Yu H, Zhang H, Dong M, Wu Z, Shen Z, Xie Y, et al. Metabolic reprogramming and AMPKalphal pathway activation by caulerpin in colorectal cancer cells. Int J Oncol (2017) 50:161-72. doi:10.3892/ijo.2016.3794

309. Molon B, Ugel S, Del Pozzo F, Soldani C, Zilio S, Avella D, et al. Chemokine nitration prevents intratumoral infiltration of antigen-specific T cells. J Exp Med (2011) 208:1949-62. doi:10.1084/jem.20101956
310. Muller AJ, DuHadaway JB, Donover PS, Sutanto-Ward E, Prendergast GC. Inhibition of indoleamine 2,3-dioxygenase, an immunoregulatory target of the cancer suppression gene Bin1, potentiates cancer chemotherapy. Nat Med (2005) 11:312-9. doi:10.1038/nm1196

311. Liu X, Shin N, Koblish HK, Yang G, Wang Q, Wang K, et al. Selective inhibition of IDO1 effectively regulates mediators of antitumor immunity. Blood (2010) 115:3520-30. doi:10.1182/blood-2009-09-246124

312. Balachandran VP, Cavnar MJ, Zeng S, Bamboat ZM, Ocuin LM, Obaid H, et al. Imatinib potentiates antitumor $\mathrm{T}$ cell responses in gastrointestinal stromal tumor through the inhibition of Ido. Nat Med (2011) 17:1094-100. doi: $10.1038 / \mathrm{nm} .2438$

313. Dietz AB, Souan L, Knutson GJ, Bulur PA, Litzow MR, Vuk-Pavlovic S. Imatinib mesylate inhibits T-cell proliferation in vitro and delayedtype hypersensitivity in vivo. Blood (2004) 104:1094-9. doi:10.1182/ blood-2003-12-4266

314. Nika K, Soldani C, Salek M, Paster W, Gray A, Etzensperger R, et al. Constitutively active Lck kinase in T cells drives antigen receptor signal transduction. Immunity (2010) 32:766-77. doi:10.1016/j.immuni.2010. 05.011

315. Luo J, Hong Y, Tao X, Wei X, Zhang L, Li Q. An indispensable role of CPT-1a to survive cancer cells during energy stress through rewiring cancer metabolism. Tumour Biol (2016) 37:15795-804. doi:10.1007/s13277-016-5382-6

316. Qian J, Chen Y, Meng T, Ma L, Meng L, Wang X, et al. Molecular regulation of apoptotic machinery and lipid metabolism by mTORC1/mTORC2 dual inhibitors in preclinical models of HER2+/PIK3CAmut breast cancer. Oncotarget (2016) 7(41):67071-86. doi:10.18632/oncotarget.11490

317. Zeng H, Yang K, Cloer C, Neale G, Vogel P, Chi H. mTORC1 couples immune signals and metabolic programming to establish $\mathrm{T}(\mathrm{reg})$-cell function. Nature (2013) 499:485-90. doi:10.1038/nature12297

318. Tontonoz P, Hu E, Spiegelman BM. Stimulation of adipogenesis in fibroblasts by PPAR gamma 2, a lipid-activated transcription factor. Cell (1994) 79:1147-56. doi:10.1016/0092-8674(94)90006-X

319. Demetri GD, Fletcher CD, Mueller E, Sarraf P, Naujoks R, Campbell N, et al. Induction of solid tumor differentiation by the peroxisome proliferatoractivated receptor-gamma ligand troglitazone in patients with liposarcoma. Proc Natl Acad Sci U S A (1999) 96:3951-6. doi:10.1073/pnas.96.7.3951

320. Tebbe C, Chhina J, Dar SA, Sarigiannis K, Giri S, Munkarah AR, et al. Metformin limits the adipocyte tumor-promoting effect on ovarian cancer. Oncotarget (2014) 5:4746-64. doi:10.18632/oncotarget.2012

321. Martinez-Outschoorn UE, Balliet RM, Rivadeneira DB, Chiavarina B, Pavlides S, Wang C, et al. Oxidative stress in cancer associated fibroblasts drives tumor-stroma co-evolution: a new paradigm for understanding tumor metabolism, the field effect and genomic instability in cancer cells. Cell Cycle (2010) 9:3256-76. doi:10.4161/cc.9.16.12553

322. Ibrahim-Hashim A, Wojtkowiak JW, de Lourdes Coelho Ribeiro M, Estrella V, Bailey KM, Cornnell HH, et al. Free base lysine increases survival and reduces metastasis in prostate cancer model. J Cancer Sci Ther (2011). doi:10.4172/1948-5956.S1-004

323. Ibrahim Hashim A, Cornnell HH, Coelho Ribeiro Mde L, Abrahams D, Cunningham J, Lloyd $M$, et al. Reduction of metastasis using a non-volatile buffer. Clin Exp Metastasis (2011) 28:841-9. doi:10.1007/ s10585-011-9415-7

324. Ibrahim-Hashim A, Cornnell HH, Abrahams D, Lloyd M, Bui M, Gillies RJ, et al. Systemic buffers inhibit carcinogenesis in TRAMP mice. J Urol (2012) 188:624-31. doi:10.1016/j.juro.2012.03.113

325. Reichert M, Steinbach JP, Supra P, Weller M. Modulation of growth and radiochemosensitivity of human malignant glioma cells by acidosis. Cancer (2002) 95:1113-9. doi:10.1002/cncr.10767

326. Gerweck LE, Vijayappa S, Kozin S. Tumor pH controls the in vivo efficacy of weak acid and base chemotherapeutics. Mol Cancer Ther (2006) 5:1275-9. doi:10.1158/1535-7163.MCT-06-0024

327. Morimura T, Fujita K, Akita M, Nagashima M, Satomi A. The proton pump inhibitor inhibits cell growth and induces apoptosis in human hepatoblastoma. Pediatr Surg Int (2008) 24:1087-94. doi:10.1007/s00383-008-2229-2

328. von Schwarzenberg K, Wiedmann RM, Oak P, Schulz S, Zischka H, Wanner G, et al. Mode of cell death induction by pharmacological vacuolar $\mathrm{H}+$-ATPase (V-ATPase) inhibition. J Biol Chem (2013) 288:1385-96. doi:10.1074/jbc. M112.412007 
329. Kastelein F, Spaander MC, Steyerberg EW, Biermann K, Valkhoff VE, Kuipers EJ, et al. Proton pump inhibitors reduce the risk of neoplastic progression in patients with Barrett's esophagus. Clin Gastroenterol Hepatol (2013) 11:382-8. doi:10.1016/j.cgh.2012.11.014

330. Ihnatko R, Kubes M, Takacova M, Sedlakova O, Sedlak J, Pastorek J, et al. Extracellular acidosis elevates carbonic anhydrase IX in human glioblastoma cells via transcriptional modulation that does not depend on hypoxia. Int J Oncol (2006) 29:1025-33. doi:10.3892/ijo.29.4.1025

331. Supuran CT. Development of small molecule carbonic anhydrase IX inhibitors. BJU Int (2008) 101(Suppl 4):39-40. doi:10.1111/j.1464-410X.2008. 07648.x

332. Lou Y, McDonald PC, Oloumi A, Chia S, Ostlund C, Ahmadi A, et al. Targeting tumor hypoxia: suppression of breast tumor growth and metastasis by novel carbonic anhydrase IX inhibitors. Cancer Res (2011) 71:3364-76. doi:10.1158/0008-5472.CAN-10-4261

333. Justus CR, Dong L, Yang LV. Acidic tumor microenvironment and pH-sensing G protein-coupled receptors. Front Physiol (2013) 4:354. doi:10.3389/ fphys.2013.00354

334. Yang L, Achreja A, Yeung TL, Mangala LS, Jiang D, Han C, et al. Targeting stromal glutamine synthetase in tumors disrupts tumor microenvironment-regulated cancer cell growth. Cell Metab (2016) 24:685-700. doi:10.1016/j.cmet.2016.10.011
335. Singh S, Pandey S, Bhatt AN, Chaudhary R, Bhuria V, Kalra N, et al. Chronic dietary administration of the glycolytic inhibitor 2-Deoxy-D-Glucose (2-DG) inhibits the growth of implanted Ehrlich's ascites tumor in mice. PLoS One (2015) 10:e0132089. doi:10.1371/journal.pone.0132089

336. Newton R, Priyadharshini B, Turka LA. Immunometabolism of regulatory T cells. Nat Immunol (2016) 17:618-25. doi:10.1038/ni.3466

337. Kelly B, O'Neill LA. Metabolic reprogramming in macrophages and dendritic cells in innate immunity. Cell Res (2015) 25:771-84. doi:10.1038/cr.2015.68

338. Pandey S, Singh S, Anang V, Bhatt AN, Natarajan K, Dwarakanath BS. Pattern recognition receptors in cancer progression and metastasis. Cancer Growth Metastasis (2015) 8:25-34. doi:10.4137/CGM.S24314

Conflict of Interest Statement: The authors declare that the research was conducted in the absence of any commercial or financial relationships that could be construed as a potential conflict of interest.

Copyright (c) 2017 Gupta, Roy and Dwarakanath. This is an open-access article distributed under the terms of the Creative Commons Attribution License (CC BY). The use, distribution or reproduction in other forums is permitted, provided the original author(s) or licensor are credited and that the original publication in this journal is cited, in accordance with accepted academic practice. No use, distribution or reproduction is permitted which does not comply with these terms. 